\title{
Exploring Natural Product Artifacts: the Polyketide Enterocin Warms to a Ballet of Isomers
}

\section{Supporting Information}

Angela A. Salim, ${ }^{\ddagger}$ Kaumadi Samarasekera, ${ }^{\ddagger}$ Zeinab G. Khalil, and Robert J. Capon*

Division of Chemistry and Structural Biology, Institute for Molecular Bioscience, The University of Queensland, St Lucia, QLD 4072, Australia

$\$$ joint first authors

Corresponding author.

* Tel +61 73346 2979. Facsimile +61 73346 2090. Email: r.capon@uq.edu.au 


\section{Table of Contents}

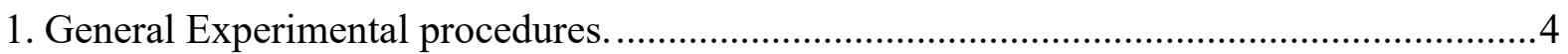

2. Collection and Taxonomy of Streptomyces sp. CMB-MRB492 ......................................

3. Scale-up cultivation of Streptomyces sp. (CMB-MRB492) and compound purification......8

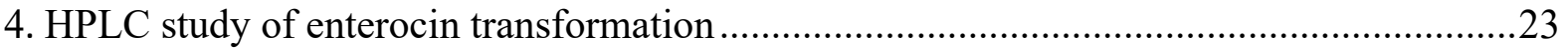

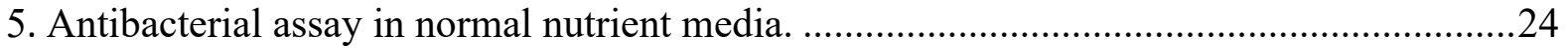

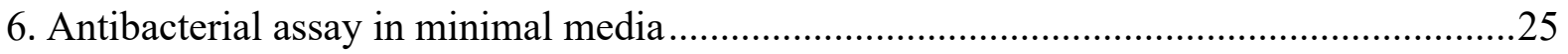

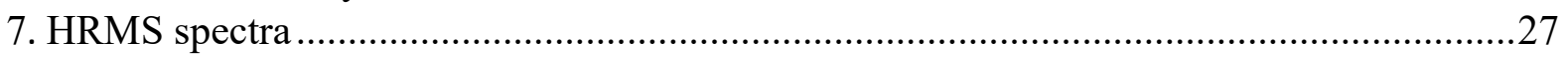

\section{List of Tables}

Table S1. Comparison of NMR data (DMSO- $\left.d_{6}\right)$ for isolated enterocin $(\mathbf{1})^{\mathrm{a}}$ and the published

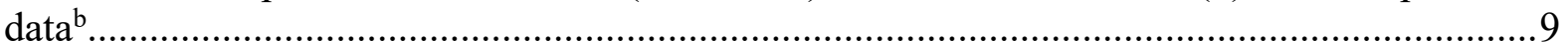

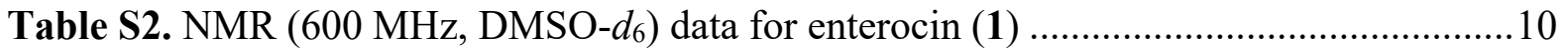

Table S3. NMR (600 MHz, DMSO- $\left.d_{6}\right)$ data for enterocin B (6) ......................................... 11

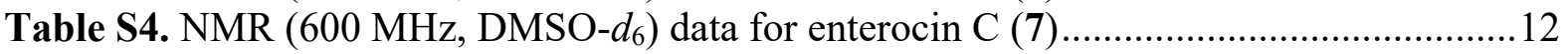

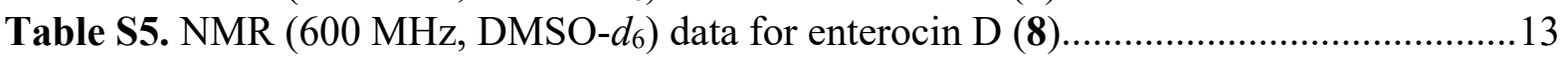

\section{List of Figures}

Figure S1. BLAST search (closest match) of CMB-MRB491 16S rRNA sequence...............6

Figure S2. Phylogenetic tree of CMB-F294, inset: CMB-MRB492 grown on ISP2 agar....... 7

Figure S3. Chromatograms (DAD $210 \mathrm{~nm}$ ) of the EtOAc extract of an ISP2 agar cultivation of CMB-MRB492 where (a) dried under $\mathrm{N}_{2}$ at r.t. (analysed using UPLC), vs (b) dried under $\mathrm{N}_{2}$ at $40{ }^{\circ} \mathrm{C}$ (analysed using LC/MS); inset UV spectra of 1 (green) and 6 and 7 (cyan).

Figure S4. Energy minimized 3D representation and ROESY correlations for enterocin B (6)

Figure S5. 3D representation and ROESY correlations for enterocin C (7) .......................... 12

Figure S6. Energy minimized 3D representation and ROESY correlations for enterocin D (8)

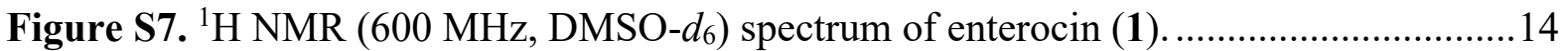

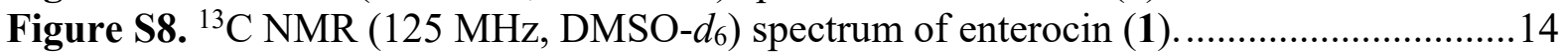

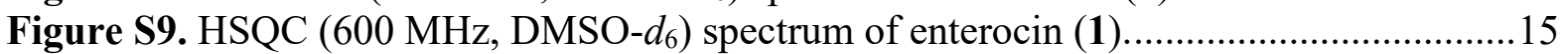

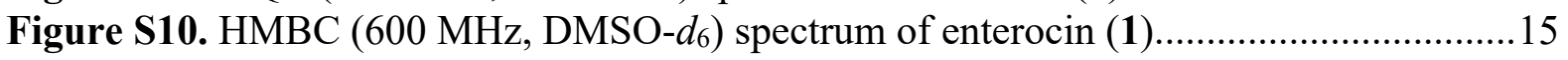

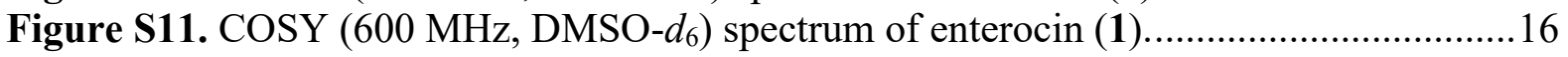

Figure S12. ROESY (600 MHz, DMSO- $\left.d_{6}\right)$ spectrum of enterocin (1) .............................16

Figure S13. ${ }^{1} \mathrm{H}$ NMR (600 MHz, DMSO- $\left.d_{6}\right)$ spectrum for enterocin B (6) (black numbering)

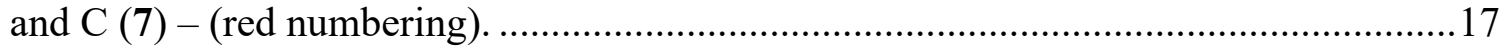

Figure S14. ${ }^{13} \mathrm{C}$ NMR $\left(125 \mathrm{MHz}\right.$, DMSO- $\left.d_{6}\right)$ spectrum for enterocin B (6) (black numbering)

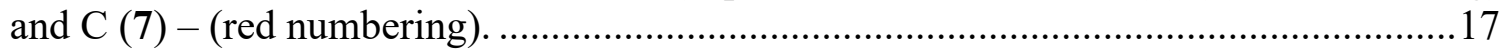

Figure S15. HSQC (600 MHz, DMSO- $\left.d_{6}\right)$ spectrum of enterocins B (6) and C (7)...........18

Figure S16. HMBC (600 MHz, DMSO- $\left.d_{6}\right)$ spectrum of enterocins B (6) and C (7)...........18

Figure S17. COSY (600 MHz, DMSO- $\left.d_{6}\right)$ spectrum of enterocins B $(6)$ and C (7) ............19

Figure S18. ROESY (600 MHz, DMSO- $\left.d_{6}\right)$ spectrum of enterocins B (6) and C (7)..........19

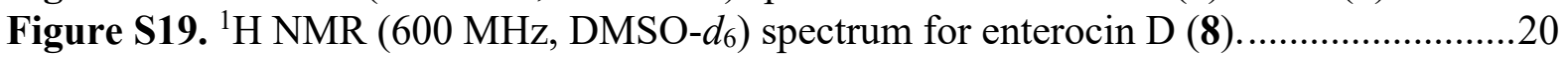

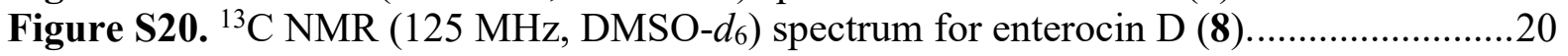

Figure S21. HSQC $\left(600 \mathrm{MHz}, \mathrm{DMSO}-d_{6}\right)$ spectrum of enterocin D (8) ............................21 


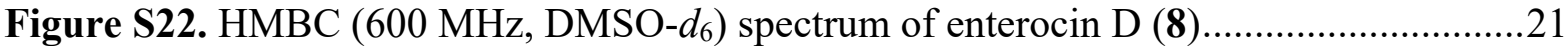

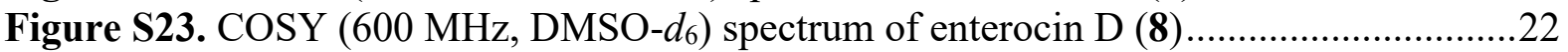

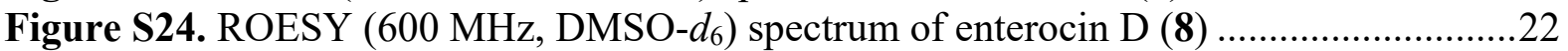

Figure S25. UPLC chromatogram of enterocin at $\mathrm{pH} 11$ (adjusted with TEA) at r.t. at different time point in $100 \% \mathrm{MeCN}$ (left) and in $\mathrm{MeCN} / \mathrm{H}_{2} \mathrm{O} 1: 1$ ratio (right)............................23

Figure S26. UV spectra of enterocin and its analogs ......................................................23

Figure S27. Antibacterial results for $\mathbf{1}$ and $\mathbf{8}$ against selected bacteria in the normal nutrient media.

Figure S28. Antibacterial results for 1, 8 and penicillin $\mathrm{G}$ (positive control) against $E$. coli in

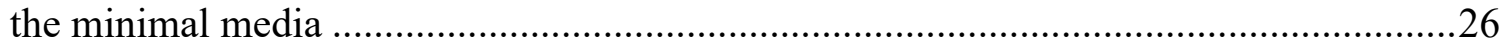

Figure S29. HRESIMS spectrum and measurement for enterocin (1) ...............................27

Figure S30. UPLC-QTOF spectrum and HRESIMS measurement for enterocin B (6) ........28

Figure S31. UPLC-QTOF spectrum and HRESIMS measurement for enterocin C (7)........29

Figure S32. HRESIMS spectrum and measurement for enterocin D (8)............................30

Figure S33. UPLC-QTOF spectrum and HRESIMS measurement for enterocin E (9)........31

Figure S34. UPLC-QTOF spectrum and HRESIMS measurement for enterocin F (10)......32 


\section{General Experimental procedures.}

Chiroptical measurements $\left([\alpha]_{\mathrm{D}}\right)$ were obtained on a JASCO P-1010 polarimeter in a $100 \times 2 \mathrm{~mm}$ cell at $20.5^{\circ} \mathrm{C}$. NMR spectra were obtained on a Bruker Advance DRX600 spectrometer, in the solvents indicated and referenced to residual signals $\left(\delta_{\mathrm{H}} 2.50\right.$ and $\delta_{\mathrm{C}} 39.15$ ppm for DMSO- $d_{6}$ ) in deuterated solvents. Electrospray ionization mass spectra (ESIMS) were acquired using Agilent 1100 Series separations module equipped with an Agilent 1100 Series LC/MS mass detector in both positive and negative ion modes under the following conditions (Zorbax SB-C $5 \mu \mathrm{m}$ column, $150 \times 4.6 \mathrm{~mm}$, eluting with $1.0 \mathrm{~mL} / \mathrm{min} 90 \% \mathrm{H}_{2} \mathrm{O} / \mathrm{MeCN}$ to $100 \% \mathrm{MeCN}$ (with isocratic $0.05 \% \mathrm{HCO}_{2} \mathrm{H}$ modifier) over $15 \mathrm{~min}$, with detection at 210 and $254 \mathrm{~nm}$. Ultra high-performance liquid chromatograms (UPLC) were obtained on Agilent 1290 infinity UPLC system composed of 1290 infinity quaternary pump, thermostat, autosampler and diode array detector (Zorbax $\mathrm{C}_{8}$ RRHD $1.8 \mu \mathrm{m}$ column, $50 \times 2.1 \mathrm{~mm}$, eluting with 0.417 $\mathrm{mL} / \mathrm{min} 90 \% \mathrm{H}_{2} \mathrm{O} / \mathrm{MeCN}$ to $100 \% \mathrm{MeCN}$ (with isocratic $0.01 \%$ TFA modifier) over $2.50 \mathrm{~min}$, with detection at 210, 254, 300 and $400 \mathrm{~nm}$ ). High-resolution ESIMS measurements were obtained on a Bruker micrOTOF mass spectrometer by direct infusion in $\mathrm{MeCN}$ at $3 \mu \mathrm{L} / \mathrm{min}$ using sodium formate clusters as an internal calibrant. Preparative and semi-preparative HPLC were performed using an Agilent 1100 Series diode array and/or multiple wavelength detectors and Agilent 1100 Series fraction collector. Molecular modelling, including energy minimized structures, were performed using Chem3D Ultra version 19 (Perkin Elmer) with MM2 energy minimization.

\section{Collection and Taxonomy of Streptomyces sp. CMB-MRB492.}

The bacteria CMB-MRB492 was isolated from a soil sample collected on May 2017 from a farm in Glenthompson, VIC, Australia, after 14 days cultivation on ISP2 agar plate at $30{ }^{\circ} \mathrm{C}$. The colonies first appear white, turning to grey and finally brown with time. Genomic DNA was extracted from the mycelia using the DNeasy Plant Mini Kit (Qiagen) as per the manufacturer's protocol. The 16S rRNA genes were amplified by PCR using the universal primers FC27 (5'-AGAGTTTGATCCTGGCTCAG-3') and RC1492 (5'TACGGCTACCTTCTTACGACTT-3') purchased from Sigma-Aldrich. The PCR mixture (50 $\mu \mathrm{L})$ contained genomic DNA ( $2 \mu \mathrm{L}, 20-40 \mathrm{ng}$ ), EmeraldAmpn GT PCR Master Mix (2X Premix) $\left(25 \mu \mathrm{L}\right.$ ), primer $\left(0.2 \mu \mathrm{M}\right.$, each), and $\mathrm{H}_{2} \mathrm{O}$ (up to $50 \mu \mathrm{L}$ ). PCR was performed using the following conditions: initial denaturation at $95^{\circ} \mathrm{C}$ for $2 \mathrm{~min}, 40$ cycles in series of $95{ }^{\circ} \mathrm{C}$ for $20 \mathrm{~s}$ (denaturation), $56{ }^{\circ} \mathrm{C}$ for $20 \mathrm{~s}$ (annealing) and $72{ }^{\circ} \mathrm{C}$ for $30 \mathrm{~s}$ (extension), followed by one 
cycle at $72{ }^{\circ} \mathrm{C}$ for $5 \mathrm{~min}$. The PCR products were purified with PCR purification kit (Qiagen) and sequenced. BLAST analysis (NCBI database) showed that the amplified 16S rRNA sequence has 99\% identity with Streptomyces malaysiensis (Figure S1\&S2) (Accession number: MT211275).

\section{S rRNA sequence of Streptomyces sp. (CMB-MRB492)}

TGCAGTCGAACGATGAACCGGTTTCGGCCGGGGATTAGTGGCGAACGGGTGAGT AACACGTGGGCAATCTGCCCTGCACTCTGGGACAAGCCCTGGAAACGGGGTCTA ATACCGGATATGACGCGTTCCCGCATGGGATTCGTGTGGAAAGCTCCGGCGGTG CAGGATGAGCCCGCGGCCTATCAGCTTGTTGGTGGGGTGATGGCCTACCAAGGC GACGACGGGTAGCCGGCCTGAGAGGGCGACCGGCCACACTGGGACTGAGACAC GGCCCAGACTCCTACGGGAGGCAGCAGTGGGGAATATTGCACAATGGGCGCAAG CCTGATGCAGCGACGCCGCGTGAGGGATGACGGCCTTCGGGTTGTAAACCTCTTT CAGCAGGGAAGAAGCGTGAGTGACGGTACCTGCAGAAGAAGCGCCGGCTAACT ACGTGCCAGCAGCCGCGGTAATACGTAGGGCGCAAGCGTTGTCCGGAATTATTG GGCGTAAAGAGCTCGTAGGCGGCTTGTCGCGTCGGATGTGAAAGCCCGGGGCTT AACTCCGGGTCTGCATTCGATACGGGCAGGCTAGAGTTCGGTAGGGGAGATCGG AATTCCTGGTGTAGCGGTGAAATGCGCAGATATCAGGAGGAACACCGGTGGCGA AGGCGGATCTCTGGGCCGATACTGACGCTGAGGAGCGAAAGCGTGGGGAGCGA ACAGGATTAGATACCCTGGTAGTCCACGCCGTAAACGTTGGGAACTAGGTGTGG GCGACATTCCCCGTTGTCCGTGCCGCA-CTAACGCATT (791 bp) 
Streptomyces malaysiensis strain T44 16S ribosomal RNA gene, partial sequence Sequence ID: KY213677.1 Length: 1422 Number of Matches: 1

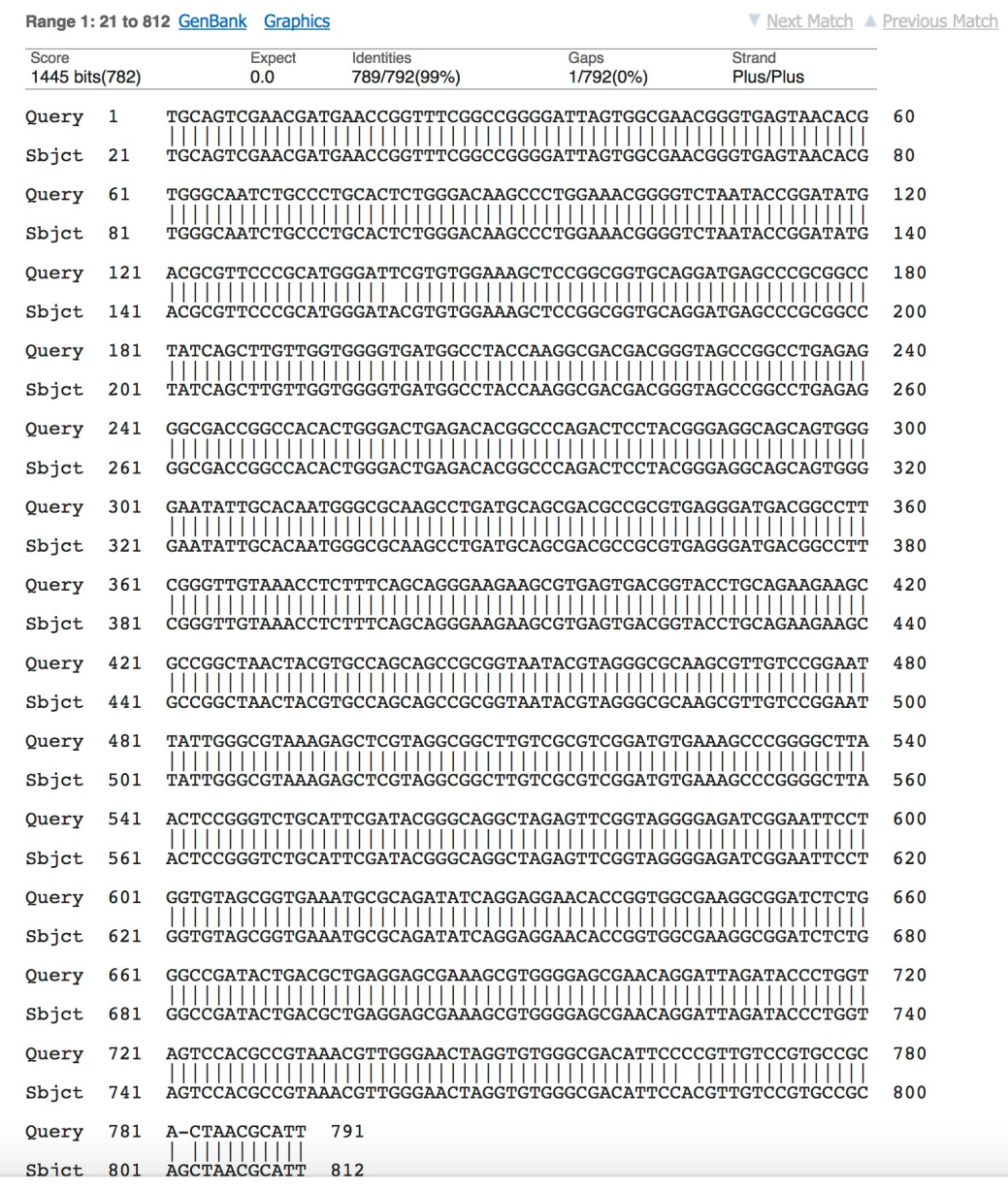

\section{Streptomyces malaysiensis strain T44 16S ribosomal RNA gene, partial sequence}

GenBank: KY213677.1

FASTA Graphics

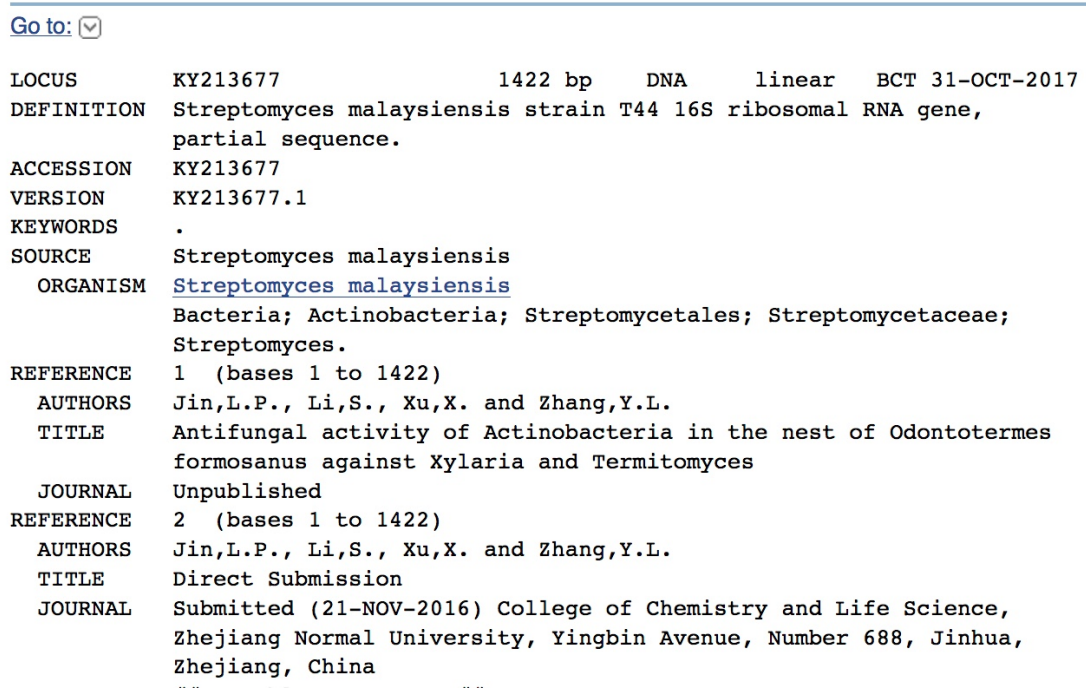

Figure S1. BLAST search (closest match) of CMB-MRB491 16S rRNA sequence 

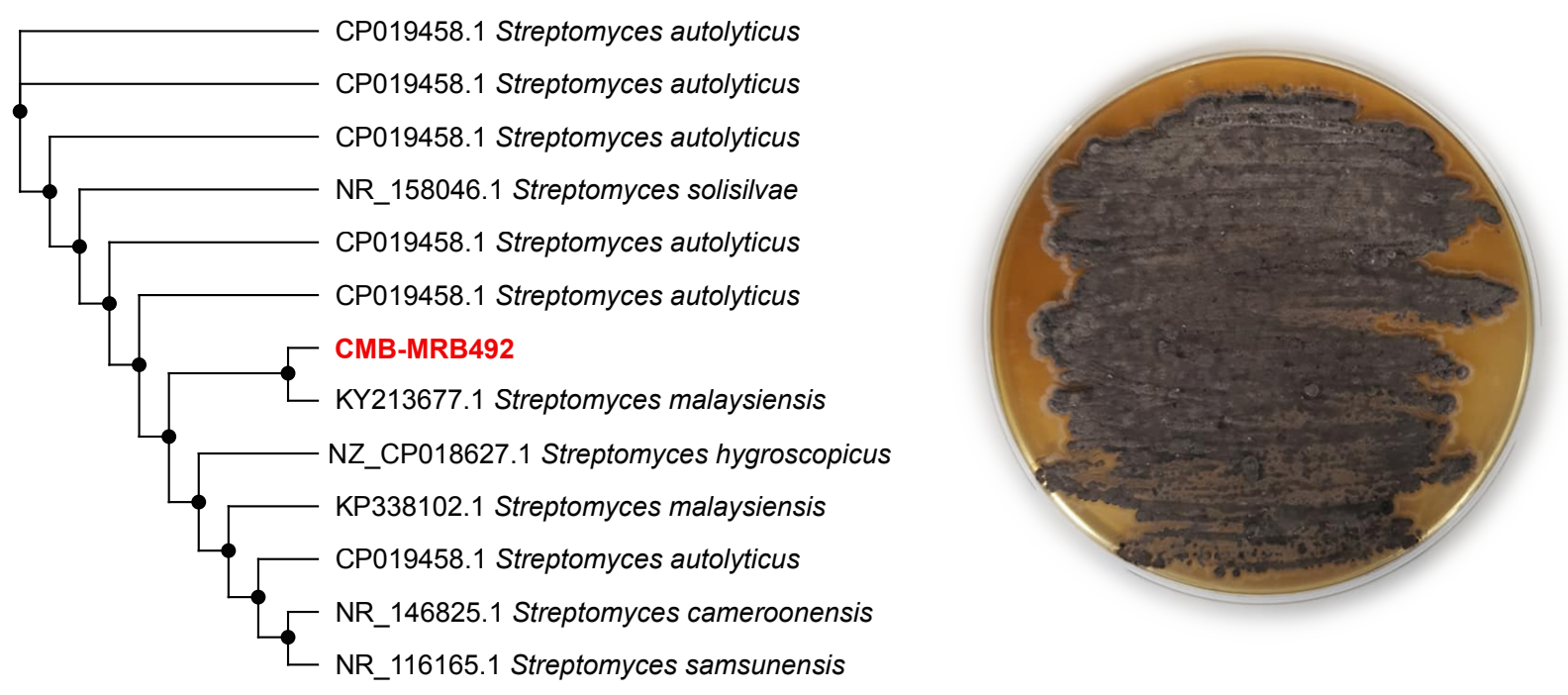

Figure S2. Phylogenetic tree of CMB-F294, inset: CMB-MRB492 grown on ISP2 agar.

Phylogenetic tree obtained by PhyML Maximum Likelihood analysis was constructed using the top similar 16S rRNA using sequences displayed after BLAST on NCBI database using CMB-MRB492 16S rRNA sequences as queries. The JC69 model was used to infer phylogeny sequences. ${ }^{1}$ Sequences alignments were produced with the MUSCLE program. ${ }^{2}$ Phylogenetic tree was constructed using the UGENE program using the aforementioned models and visualized using Ugene's tree view. ${ }^{3}$

${ }^{1}$ Yang, Z.; Goldman, N.; Friday, A. Mol. Biol. Evol. 1994, 11 (2), 316.

${ }^{2}$ Edgar, R. C. BMC Bioinformatics 2004, 5 (1), 113.

${ }^{3}$ Okonechnikov, K.; Golosova, O.; Fursov, M.; UGENE team. Bioinformatics 2012, 28 (8), 1166.

(a)

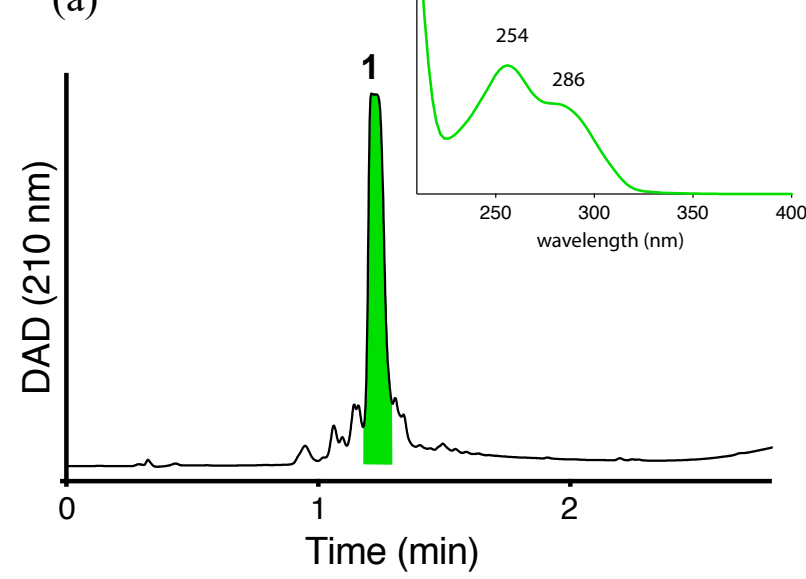

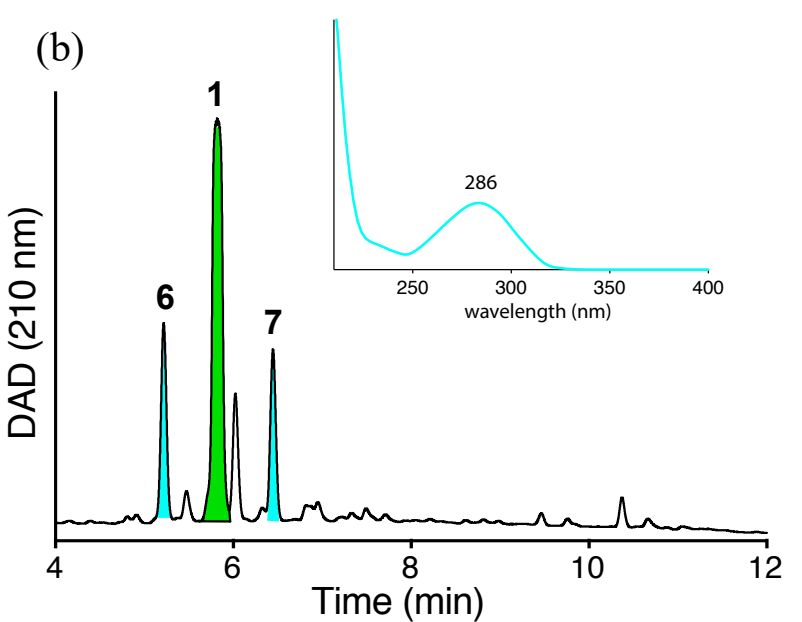

Figure S3. Chromatograms (DAD $210 \mathrm{~nm}$ ) of the EtOAc extract of an ISP2 agar cultivation of CMB-MRB492 where (a) dried under $\mathrm{N}_{2}$ at r.t. (analysed using UPLC), vs (b) dried under $\mathrm{N}_{2}$ at $40{ }^{\circ} \mathrm{C}$ (analysed using LC/MS); inset UV spectra of $\mathbf{1}$ (green) and $\mathbf{6}$ and 7 (cyan). 


\section{Scale-up cultivation of Streptomyces sp. (CMB-MRB492) and compound purification.}

Streptomyces sp. CMB-MRB492 was cultivated on SDA agar plates $(\times 100)$, incubated at $30{ }^{\circ} \mathrm{C}$ for $14 \mathrm{~d}$. Following the incubation period, the agar was diced $\left(\sim 1.5 \mathrm{~cm}^{2}\right)$ and extracted with EtOAc (batches of 50 plates with $3 \times 600 \mathrm{~mL}$ ). The combined organic phase was concentrated in vacuo at $40{ }^{\circ} \mathrm{C}$ to yield a crude extract $(310 \mathrm{mg})$, which was further partitioned between $n$-hexane $(3 \times 50 \mathrm{~mL})$ and $90 \%$ aqueous $\mathrm{MeOH}(50 \mathrm{~mL})$ and concentrated in vacuo to yield $n$-hexane $(62.5 \mathrm{mg})$ and $\mathrm{MeOH}_{\mathrm{aq}}(228 \mathrm{mg})$ solubles. A portion of the $\mathrm{MeOH}$ solubles (50 mg) were fractionated by preparative HPLC chromatography (Phenomenex $\mathrm{C}_{8}$ column, 9.4 $\times 250 \mathrm{~mm}, 10 \mu \mathrm{m}, 20 \mathrm{~mL} / \mathrm{min}$, gradient elution from $90 \% \mathrm{H}_{2} \mathrm{O} / \mathrm{MeCN}$ to $100 \% \mathrm{MeCN}$ in 30 min with constant $0.01 \%$ TFA as a modifier) to yield 14 fractions. Fraction F3 consists of pure enterocin (1) $(6.1 \mathrm{mg}, 9.0 \%)$, while F4 $(8.0 \mathrm{mg})$ was subjected to further chromatographic fractionation using semi-preparative HPLC (Zorbax RX-C 18 column, $9.4 \times 250 \mathrm{~mm}, 5 \mu \mathrm{m}, 3$ $\mathrm{mL} / \mathrm{min}$, isocratic elution with $15 \% \mathrm{H}_{2} \mathrm{O} / \mathrm{MeCN}$ with $0.01 \%$ TFA as a modifier for $45 \mathrm{~min}$ ) to yield enterocin B (6) (2.2 mg, 3.2\%, not stable, quickly equilibrated into a mixture of enterocins $\mathrm{B}$ and $\mathrm{C}$ ) and enterocin C (7) (2.6 mg, 3.8\%, not stable, quickly equilibrated into a mixture of enterocins B and C). (NOTE: \% yields are weight to weight estimates based on the total crude EtOAc extract). A portion of enterocins B and C mixture $(1.0 \mathrm{mg})$ was dissolved in $\mathrm{MeCN}(0.5$ $\mathrm{mL}$ ), heated at $40{ }^{\circ} \mathrm{C}$ for $16 \mathrm{~h}$, followed by solvent removal under a stream of $\mathrm{N}_{2}$ gas at $40{ }^{\circ} \mathrm{C}$ to yield enterocin D $(\mathbf{8})$.

Enterocin (1): white powder; $[\alpha]^{25} \mathrm{D}-24(c$ 0.070, MeOH); 1D and 2D NMR (DMSO$\left.d_{6}\right)$ see Tables 1-2 and S1-2, Figures S7-S12; HRMS(ESI) $m / z$ : $[\mathrm{M}+\mathrm{Na}]^{+}$Calcd for $\mathrm{C}_{22} \mathrm{H}_{20} \mathrm{O}_{10} \mathrm{Na}$ 467.0949; found 467.0956.

Enterocin B (6): white powder, isolated as a mixture with enterocin C; 1D and 2D NMR (DMSO- $d_{6}$ ) see Tables 1-2 and S3, Figures S13-S18; HRMS(ESI) $m / z$ : $[\mathrm{M}+\mathrm{H}]^{+}$Calcd for $\mathrm{C}_{22} \mathrm{H}_{21} \mathrm{O}_{10}$ 445.1129; found 445.1111 .

Enterocin $C$ (7): white powder, isolated as a mixture with enterocin B; 1D and 2D NMR (DMSO- $d_{6}$ ) see Tables 1-2 and S4; Figures S13-S18; HRMS(ESI) $m / z$ : $[\mathrm{M}+\mathrm{H}]^{+}$Calcd for $\mathrm{C}_{22} \mathrm{H}_{21} \mathrm{O}_{10}$ 445.1129; found 445.1137 .

Enterocin D (8): white powder; $[\alpha]^{25} \mathrm{D}-44$ (c 0.070, $\left.\mathrm{MeOH}\right)$; $1 \mathrm{D}$ and 2D NMR (DMSO$d_{6}$ ) see Tables 1-2 and S5, Figures S19-S24; HRMS(ESI) $m / z$ : $[\mathrm{M}+\mathrm{Na}]^{+} \mathrm{Calcd}$ for $\mathrm{C}_{22} \mathrm{H}_{20} \mathrm{O}_{10} \mathrm{Na}$ 467.0949; found 467.0945.

Enterocin E (9): not isolated; HRMS(ESI) $m / z$ : [M+H] ${ }^{+}$Calcd for $\mathrm{C}_{22} \mathrm{H}_{21} \mathrm{O}_{10} 445.1129$; found 445.1132 .

Enterocin F (10): not isolated; HRMS(ESI) $m / z$ : $[\mathrm{M}+\mathrm{H}]^{+}$Calcd for $\mathrm{C}_{22} \mathrm{H}_{21} \mathrm{O}_{10} 445.1129$; found 445.1129 . 
Table S1. Comparison of NMR data (DMSO- $\left.d_{6}\right)$ for isolated enterocin $(\mathbf{1})^{\mathrm{a}}$ and the published data $^{\mathrm{b}}$

\begin{tabular}{|c|c|c|c|c|}
\hline \multirow[t]{2}{*}{ No. } & \multicolumn{2}{|r|}{ Experimental $^{\mathrm{a}}$} & \multicolumn{2}{|r|}{ Published $^{\mathrm{b}}$} \\
\hline & $\delta_{\mathrm{C}}$ & $\delta_{\mathrm{H},}$ multi, $(J$ in $\mathrm{Hz})$ & $\delta c^{c}$ & $\delta_{\mathrm{H}, \text { multi, },(J \text { in Hz})^{\mathrm{d}}}$ \\
\hline 1 & 173.7 & & 173.4 & \\
\hline 2 & 79.8 & & 79.6 & \\
\hline 3 & 53.0 & $4.47, \mathrm{~s}$ & 52.9 & $4.47, \mathrm{~m}$ \\
\hline 4 & 78.2 & & 78.1 & \\
\hline 5 & 69.3 & $4.47, \mathrm{dd}(5.7,4.4)$ & 69.2 & $4.47, \mathrm{~m}$ \\
\hline 6 & 75.4 & 4.65, ddd $(4.4,3.0,2.8)$ & 75.3 & $4.66, \mathrm{~m}$ \\
\hline 7 & 35.6 & 2.29, dd $(14.4,3.0)$ & 35.5 & 2.27 br d (14.4) \\
\hline & & 1.66 , ddd $(14.4,2.8,2.2)$ & & 1.68, br d (14.4) \\
\hline 8 & 76.4 & & 76.2 & \\
\hline 9 & 54.7 & $4.67, \mathrm{~d}(2.2)$ & 54.6 & $4.66, \mathrm{~m}$ \\
\hline 10 & 161.6 & & 161.2 & \\
\hline 11 & 104.7 & $6.29, \mathrm{~d}(2.2)$ & 104.6 & $6.29, \mathrm{~d}(2.3)$ \\
\hline 12 & 170.7 & & 170.4 & \\
\hline 13 & 87.8 & $5.62, \mathrm{~d}(2.2)$ & 87.6 & $5.61, \mathrm{~d}(2.3)$ \\
\hline 14 & 163.3 & & 163.0 & \\
\hline 15 & 194.9 & & 194.7 & \\
\hline 16 & 139.6 & & 139.3 & \\
\hline 17,21 & 127.9 & $7.78, \mathrm{dd}(8.5,1.2)$ & 127.7 & 7.45-7.85, m \\
\hline 18,19 & 128.4 & $7.51, \mathrm{dd}(8.5,7.5)$ & 128.0 & 7.45-7.85, m \\
\hline 19 & 132.6 & $7.60, \operatorname{td}(7.5,1.2)$ & 132.4 & 7.45-7.85, m \\
\hline $12-\mathrm{OMe}$ & 56.3 & $3.82, \mathrm{~s}$ & 56.1 & $3.87, \mathrm{~s}$ \\
\hline $2-\mathrm{OH}$ & & $5.86, \mathrm{~s}$ & & $5.85, \mathrm{~s}$ \\
\hline $4-\mathrm{OH}$ & & $5.48, \mathrm{~s}$ & & $5.46, \mathrm{~s}$ \\
\hline $5-\mathrm{OH}$ & & $5.66, \mathrm{~d}(5.7)$ & & $5.65, \mathrm{~d}(5.5)$ \\
\hline $8-\mathrm{OH}$ & & $5.91, \mathrm{~s}$ & & $5.90, \mathrm{~s}$ \\
\hline
\end{tabular}

${ }^{a}$ Data was acquired at $600 \mathrm{MHz}$ NMR

${ }^{\mathrm{b}}$ Data was acquired at $100 \mathrm{MHz}$ NMR (Seto, H. et al, Tetrahedron Lett. 1976, 48, 4367-4370)

${ }^{\mathrm{c}}$ Some of the carbons were not assigned in the original publication

${ }^{\mathrm{d}}$ Some of the protons were not assigned in the original publication 
Table S2. NMR (600 MHz, DMSO- $\left.d_{6}\right)$ data for enterocin (1)

\begin{tabular}{|c|c|c|c|c|c|}
\hline No. & $\delta_{\mathrm{C}}$ & $\delta_{\mathrm{H},}$ multi, $(J$ in $\mathrm{Hz})$ & COSY & $\mathrm{HMBC}$ & ROESY \\
\hline 1 & 173.7 & & & & \\
\hline 2 & 79.8 & & & & \\
\hline 3 & 53.0 & $4.47, \mathrm{~s}$ & & $1,2,4,5,8,9,15$ & $17,2-\mathrm{OH}, 4-\mathrm{OH}$ \\
\hline 4 & 78.2 & & & & \\
\hline 5 & 69.3 & $4.47, \mathrm{dd}(5.7,4.4)$ & $6,5-\mathrm{OH}$ & $3,4,6$ & $6,7 \alpha, 22,5-\mathrm{OH}$ \\
\hline 6 & 75.4 & 4.65, ddd $(4.4,3.0,2.8)$ & $5,7 \alpha, 7 \beta$ & $1,4,5,7,8$ & $7 \alpha, 7 \beta, 5-\mathrm{OH}$ \\
\hline 7 & 35.6 & $\alpha 2.29, \mathrm{dd}(14.4,3.0)$ & $6,7 \beta$ & $2,8,9$ & 5,6 \\
\hline & & $\beta 1.66, \operatorname{ddd}(14.4,2.8,2.2)$ & $6,7 \alpha, 9$ & $5,8,9$ & 6 \\
\hline 8 & 76.4 & & & & \\
\hline 9 & 54.7 & $4.67, \mathrm{~d}(2.2)$ & $7 \beta$ & 10 & $11,2-\mathrm{OH}, 4-\mathrm{OH}, 8-\mathrm{OH}$ \\
\hline 10 & 161.6 & & & & \\
\hline 11 & 104.7 & $6.29, \mathrm{~d}(2.2)$ & 13 & $9,10,12$ & $5,9,8-\mathrm{OH} 12-\mathrm{OMe}$ \\
\hline 12 & 170.7 & & & & \\
\hline 13 & 87.8 & $5.62, \mathrm{~d}(2.2)$ & 11 & 12,14 & 12-OMe \\
\hline 14 & 163.3 & & & & \\
\hline 15 & 194.9 & & & & \\
\hline 16 & 139.6 & & & & \\
\hline 17,21 & 127.9 & $7.78, \mathrm{dd}(8.5,1.2)$ & 18 & $15,17,19$ & $3,2-\mathrm{OH}, 4-\mathrm{OH}$ \\
\hline 18,20 & 128.4 & $7.51, \mathrm{dd}(8.5,7.5)$ & 17,19 & 16,18 & \\
\hline 19 & 132.6 & $7.60, \operatorname{td}(7.5,1.2)$ & 18 & 17 & \\
\hline 12-OMe & 56.3 & $3.82, \mathrm{~s}$ & & 12 & 11,13 \\
\hline 2-OH & & $5.86, \mathrm{~s}$ & & $1,2,3,8$ & $3,9,17$ \\
\hline $4-\mathrm{OH}$ & & $5.48, \mathrm{~s}$ & & $3,4,5,9$ & $3,9,17$ \\
\hline $5-\mathrm{OH}$ & & $5.66, \mathrm{~d}(5.7)$ & 5 & $4,5,6$ & 5,6 \\
\hline $8-\mathrm{OH}$ & & $5.91, \mathrm{~s}$ & & $7,8,9$ & 9,11 \\
\hline
\end{tabular}

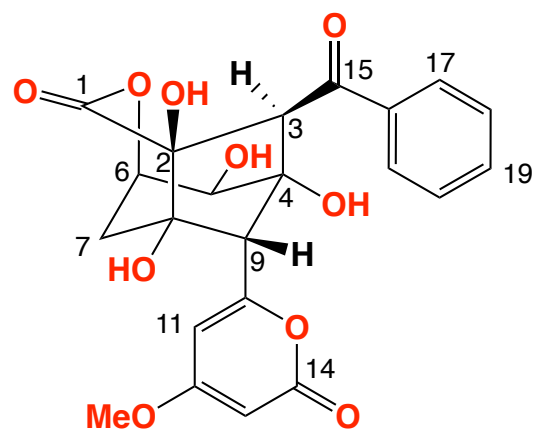


Table S3. NMR (600 MHz, DMSO- $d_{6}$ ) data for enterocin B (6)

\begin{tabular}{|c|c|c|c|c|c|}
\hline No. & $\delta_{\mathrm{C}}$ & $\delta_{\mathrm{H},}$ multi, $(J$ in $\mathrm{Hz})$ & COSY & HMBC & ROESY \\
\hline 1 & 170.9 & & & & \\
\hline 2 & 80.2 & & & & \\
\hline 3 & 66.0 & $2.70, \mathrm{~d},(2.1)$ & 5 & $2,4,8,16$ & 9,17 \\
\hline 4 & 81.8 & & & & \\
\hline 5 & 81.5 & $4.84, \mathrm{dd}(4.2,2.1)$ & 3,6 & $3,6,15$ & $6,7 \alpha, 9,11$ \\
\hline 6 & 72.1 & 4.28, ddd $(4.4,2.8,2.4)$ & $5,7 \alpha, 7 \beta$ & 4,8 & $5,7 \alpha, 7 \beta$ \\
\hline 7 & 32.7 & $\alpha 1.74, \mathrm{dd}(14.4,2.8)$ & $6,7 \beta$ & $5,6,8,9$ & $5,6,7 \beta, 9$ \\
\hline & & $\beta 2.60, \mathrm{dd}(14.4,2.4,1.7)$ & $6,7 \alpha$ & 2,8 & $6,7 \alpha$ \\
\hline 8 & 78.7 & & & & \\
\hline 9 & 53.1 & $3.63, \mathrm{~d}(1.7)$ & & $4,7,8,10$ & $3,5,7 \alpha, 11$ \\
\hline 10 & 161.9 & & & & \\
\hline 11 & 104.3 & $6.17, \mathrm{~d}(2.2)$ & 13 & $9,10,12,13$ & $5,7 \alpha, 9,12-\mathrm{OMe}$ \\
\hline 12 & 170.8 & & & & \\
\hline 13 & 87.6 & $5.63, \mathrm{~d}(2.2)$ & 11 & $11,12,14$ & 12-OMe \\
\hline 14 & 163.3 & & & & \\
\hline 15 & 107.2 & & & & \\
\hline 16 & 136.2 & & & & \\
\hline 17,21 & 126.9 & 7.54, d (7.4) & 18 & $15,19,17$ & 3 \\
\hline 18,20 & 127.2 & $7.34, \mathrm{~m}$ & 17 & 16,18 & \\
\hline 19 & 128.2 & $7.34, \mathrm{~m}$ & & 17 & \\
\hline 12-OMe & 56.3 & $3.83, \mathrm{~s}$ & & & 11,13 \\
\hline $2-\mathrm{OH}$ & & n.d. & & & \\
\hline $4-\mathrm{OH}$ & & n.d. & & & \\
\hline 8-OH & & n.d. & & & \\
\hline $15-\mathrm{OH}$ & & n.d. & & & \\
\hline
\end{tabular}

n.d.: not detected in the spectrum
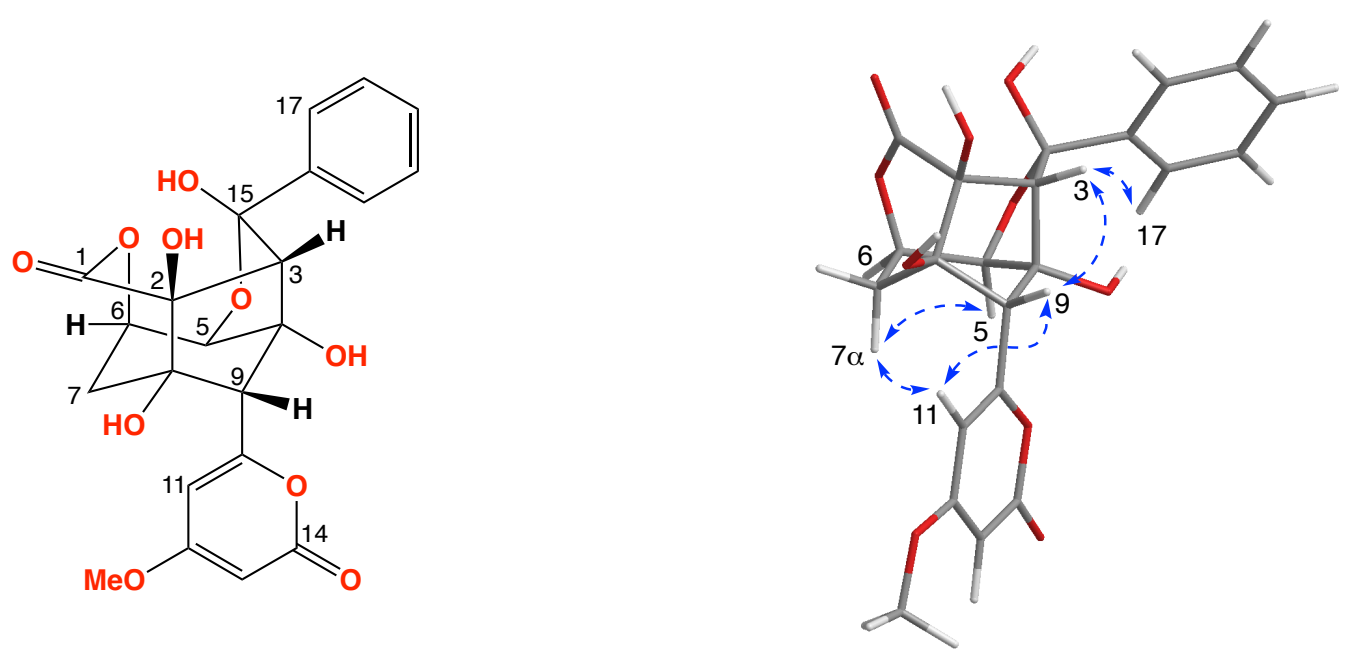

Figure S4. Energy minimized 3D representation and ROESY correlations for enterocin B (6) 
Table S4. NMR (600 MHz, DMSO- $d_{6}$ ) data for enterocin C (7)

\begin{tabular}{|c|c|c|c|c|c|}
\hline No. & $\delta_{\mathrm{C}}$ & $\delta_{\mathrm{H},}$ multi, $(J$ in $\mathrm{Hz})$ & COSY & HMBC & ROESY \\
\hline 1 & 174.2 & & & & \\
\hline 2 & 82.9 & & & & \\
\hline 3 & 68.2 & $3.10, \mathrm{~s}$ & & $1,2,4,5,8,16$ & $9,17,2-\mathrm{OH}, 4-\mathrm{OH}$ \\
\hline 4 & 83.7 & & & & \\
\hline 5 & 90.0 & $4.59, \mathrm{~d}(5.1)$ & 6 & $3,4,6,7,15$ & $6,11,17,4-\mathrm{OH}$ \\
\hline 6 & 62.5 & $\begin{array}{l}3.98, \text { dddd } \\
(10.1,9.2,5.8,5.1)\end{array}$ & $5,7 \alpha, 7 \beta, 6-\mathrm{OH}$ & 7 & $5,7 \alpha, 11$ \\
\hline 7 & 37.1 & $\alpha 2.24, \mathrm{dd}(15.2,10.1)$ & $6,7 \beta$ & $2,5,6,8$ & $6,7 \beta, 9,11$ \\
\hline 8 & 77.4 & $\beta 1.49, \mathrm{dd}(15.2,9.2)$ & $6,7 \alpha$ & $2,6,8,9$ & $7 \alpha$ \\
\hline 9 & 53.5 & $3.62, \mathrm{~s}$ & & $4,5,7,8,10,11$ & $3,5,7 \alpha, 11$ \\
\hline 10 & 161.0 & & & & \\
\hline 11 & 101.7 & $6.36, \mathrm{dd}(2.1,1.4)$ & 13 & $9,10,12,13$ & $5,6,7 \alpha, 9,12-\mathrm{OMe}$ \\
\hline 12 & 170.7 & & & & \\
\hline 13 & 88.1 & $5.63, \mathrm{~d}(2.1)$ & 11 & $11,12,14$ & $12-\mathrm{OMe}$ \\
\hline 14 & 163.1 & & & & \\
\hline 15 & 112.0 & & & & \\
\hline 16 & 140.2 & & & & \\
\hline 17,21 & 125.4 & $7.54, \mathrm{~d}(7.5)$ & 18 & $15,17,19$ & 3,5 \\
\hline 18,20 & 128.3 & 7.46 , dd $(7.5,7.5)$ & 17,19 & 16,18 & \\
\hline 19 & 128.8 & $7.41, \mathrm{dd}(7.5,7.5)$ & 18 & 17 & \\
\hline 12-OMe & 56.4 & $3.82, \mathrm{~s}$ & & 12 & 11,13 \\
\hline $2-\mathrm{OH}$ & & $6.72, \mathrm{~s}$ & & $2,3,8$ & 3 \\
\hline $4-\mathrm{OH}$ & & $6.13, \mathrm{~s}$ & & $3,4,5$ & 3,5 \\
\hline $6-\mathrm{OH}$ & & $4.85, \mathrm{~d}(5.8)$ & 6 & $5,6,7$ & \\
\hline $8-\mathrm{OH}$ & & $5.66, \mathrm{~s}$ & & 7 & \\
\hline
\end{tabular}
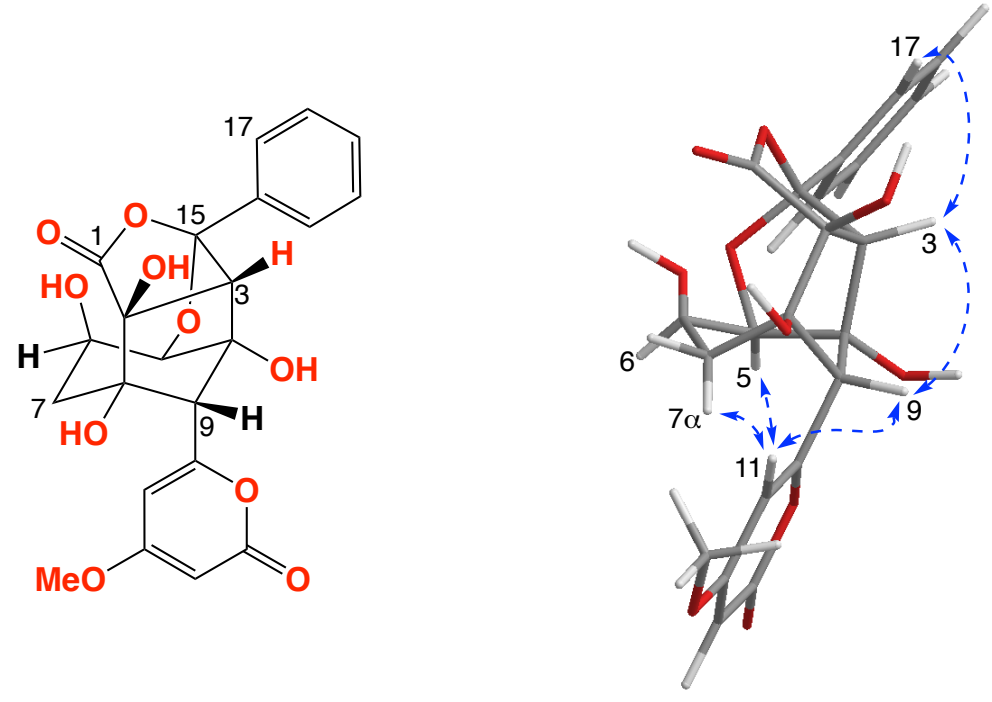

Figure S5. 3D representation and ROESY correlations for enterocin C (7) 
Table S5. NMR (600 MHz, DMSO- $\left.d_{6}\right)$ data for enterocin D (8)

\begin{tabular}{|c|c|c|c|c|c|}
\hline No. & $\delta \mathrm{C}$ & $\delta_{\mathrm{H},}$, multi, $(J$ in $\mathrm{Hz})$ & $\mathrm{COSY}$ & HMBC & ROESY \\
\hline 1 & 175.7 & - & & & \\
\hline 2 & 88.1 & - & & & \\
\hline 3 & 66.8 & $3.11, \mathrm{~s}$ & - & $2,4,5,8,16$ & $9,17,4-\mathrm{OH}$ \\
\hline 4 & 85.7 & - & & & \\
\hline 5 & 90.2 & $4.49, \mathrm{~d}(4.9)$ & 6 & $4,6,7,15$ & $6,17,4-\mathrm{OH}$ \\
\hline 6 & 63.8 & $\begin{array}{l}3.62 \text {, dddd }(9.8,9.5,5.7 \\
4.9)\end{array}$ & $5,7 \alpha, 7 \beta, 6-\mathrm{OH}$ & & $5,7 \alpha, 11,6-\mathrm{OH}$ \\
\hline \multirow[t]{2}{*}{7} & 35.0 & $\alpha 2.27, \mathrm{dd}(14.7,9.8)$ & $6,7 \beta$ & $2,5,6,8$ & $6,9,11,6-\mathrm{OH}$ \\
\hline & & $\beta 1.38, \mathrm{dd}(14.7,9.5)$ & $6,7 \alpha$ & $2,5,8,9$ & $6-\mathrm{OH}$ \\
\hline 8 & 83.9 & - & & & \\
\hline 9 & 52.1 & $3.93, \mathrm{~s}$ & & $4,5,7,8,10,11$ & $3,7 \alpha, 11,4-\mathrm{OH}$ \\
\hline 10 & 162.7 & - & & & \\
\hline 11 & 100.0 & $6.33, \mathrm{dd}(2.0,2.0)$ & 13 & $9,10,12,13$ & $5,6,7 \alpha, 9,12-\mathrm{OMe}$ \\
\hline 12 & 170.4 & - & & & \\
\hline 13 & 87.3 & $5.48, \mathrm{~d}(2.0)$ & 11 & $11,12,14$ & 12-OMe \\
\hline 14 & 163.4 & - & & & \\
\hline 15 & 111.9 & - & & & \\
\hline 16 & 140.9 & - & & & \\
\hline 17,21 & 125.3 & $7.52, \mathrm{~d}(7.4)$ & 18 & $15,17,19$ & $3,5,4-\mathrm{OH}$ \\
\hline 18,20 & 128.3 & $7.45, \mathrm{dd}(7.4,7.4)$ & 17,19 & 16,18 & \\
\hline 19 & 128.6 & $7.40, \mathrm{dd}(7.4,7.4)$ & 18 & 17 & \\
\hline 12-OMe & 55.8 & $3.66, \mathrm{~s}$ & & 12 & 11,13 \\
\hline $2-\mathrm{OH}$ & & $6.54, \mathrm{~s}$ & & & \\
\hline $4-\mathrm{OH}$ & & $6.00, \mathrm{~s}$ & & 4,5 & $3,5,9,17$ \\
\hline $6-\mathrm{OH}$ & & $4.75, \mathrm{~d}(5.7)$ & 6 & $5,6,7$ & $6,7 \alpha, 7 \beta$ \\
\hline $8-\mathrm{OH}$ & & $6.54, \mathrm{~s}$ & & & \\
\hline
\end{tabular}
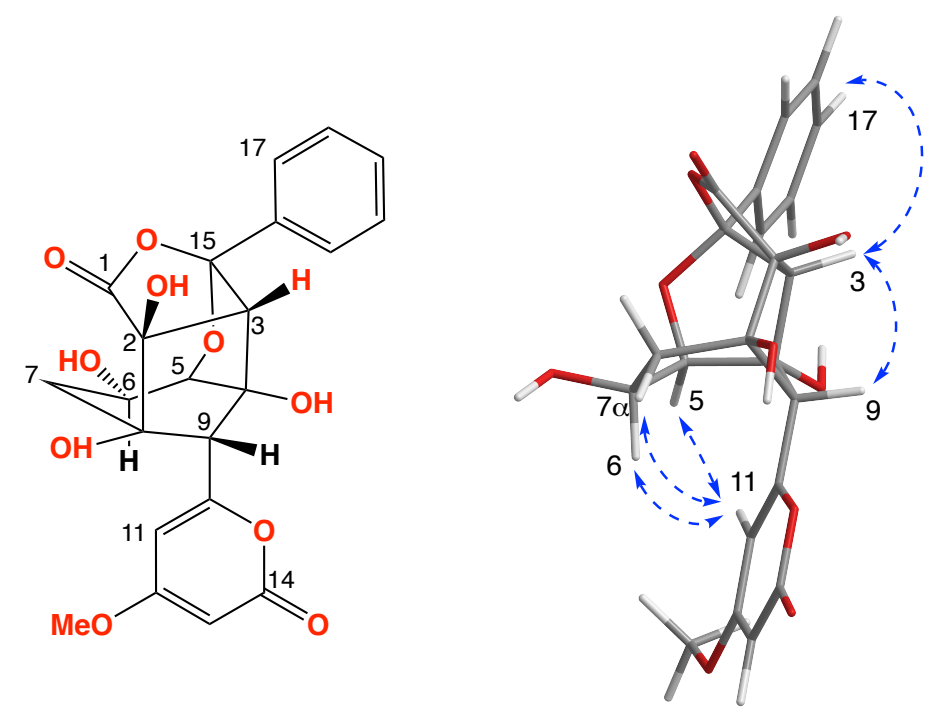

Figure S6. Energy minimized 3D representation and ROESY correlations for enterocin D (8) 


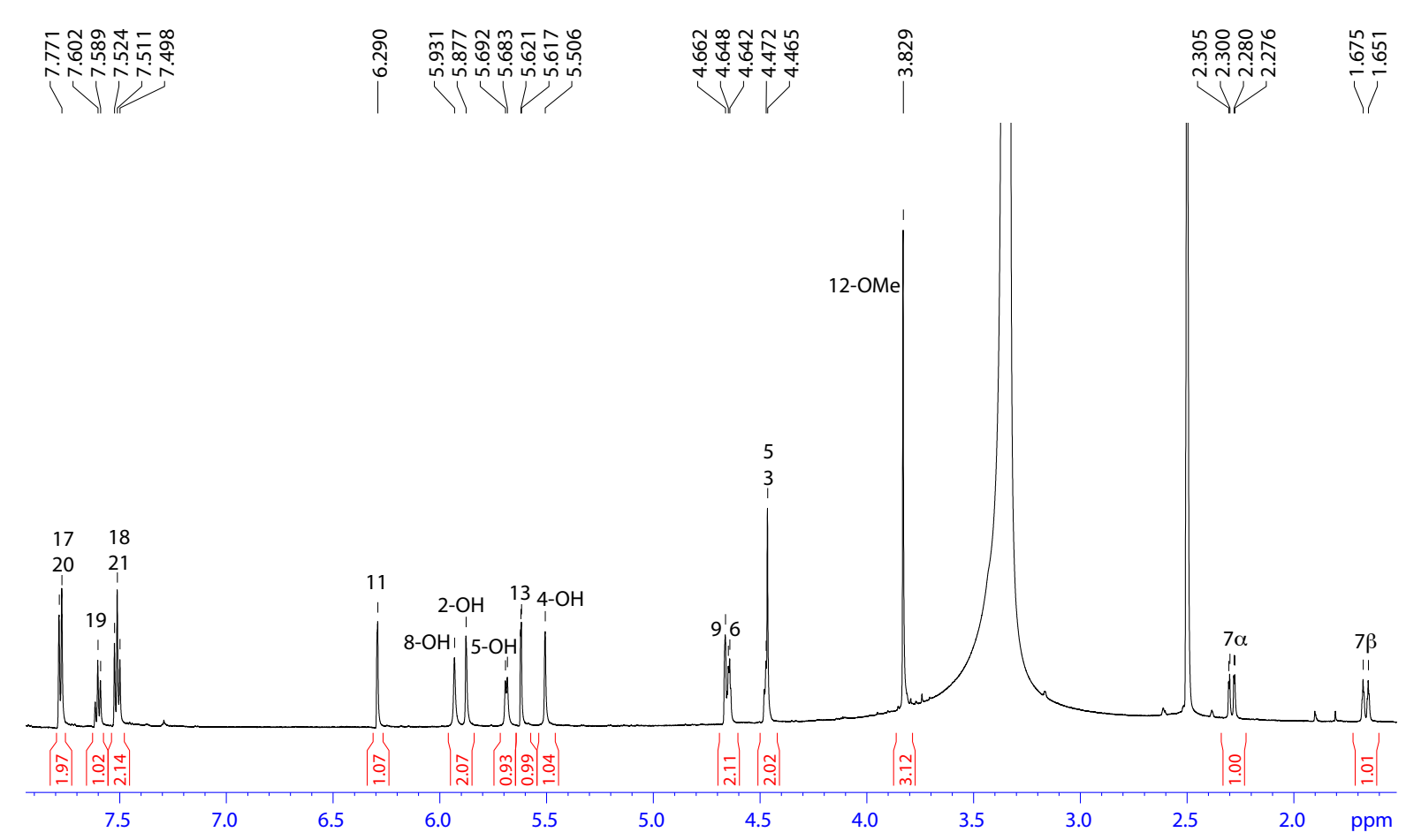

Figure S7. ${ }^{1} \mathrm{H}$ NMR (600 MHz, DMSO- $d_{6}$ ) spectrum of enterocin (1).

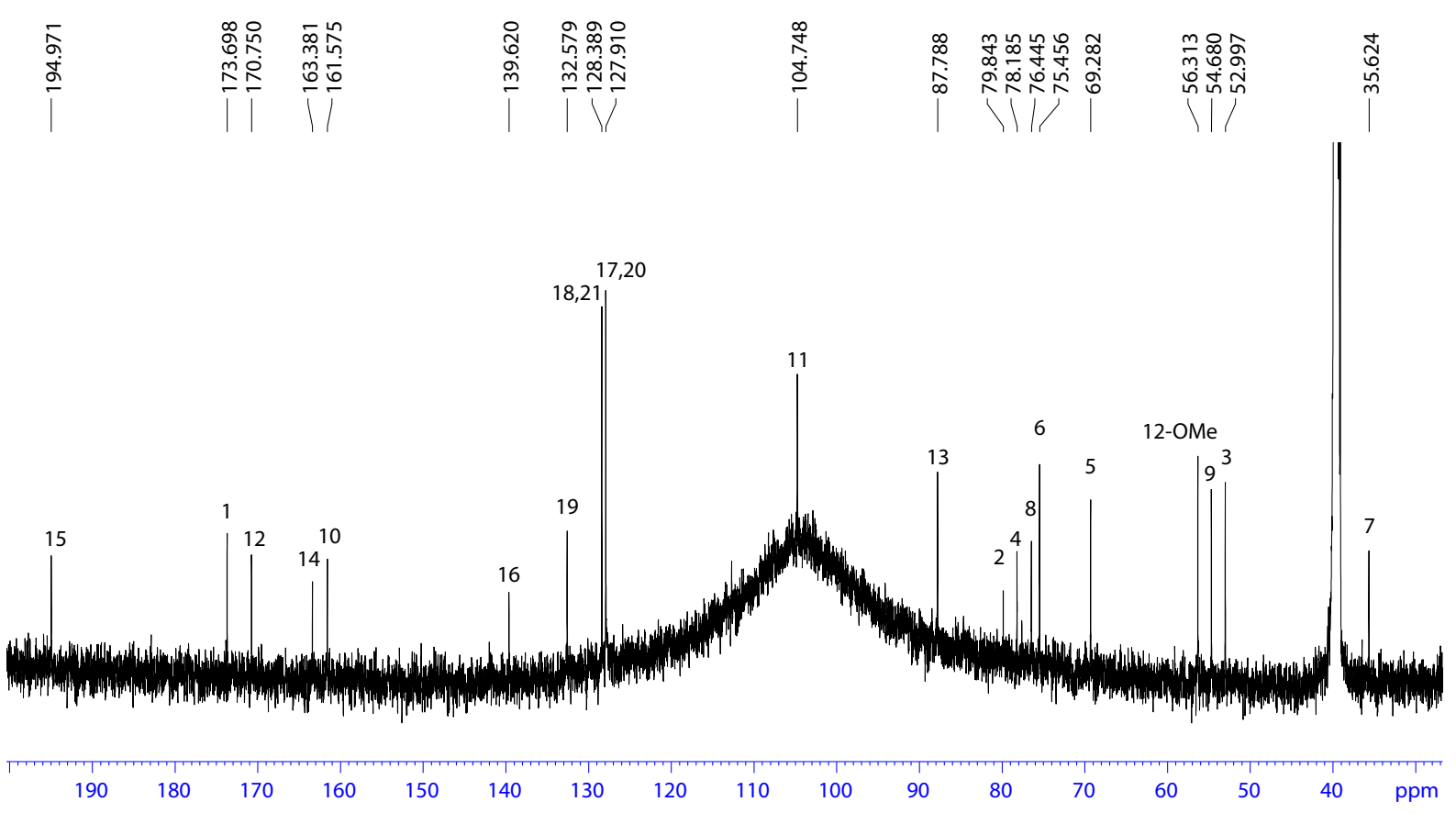

Figure S8. ${ }^{13} \mathrm{C}$ NMR $\left(125 \mathrm{MHz}\right.$, DMSO- $\left.d_{6}\right)$ spectrum of enterocin (1). 


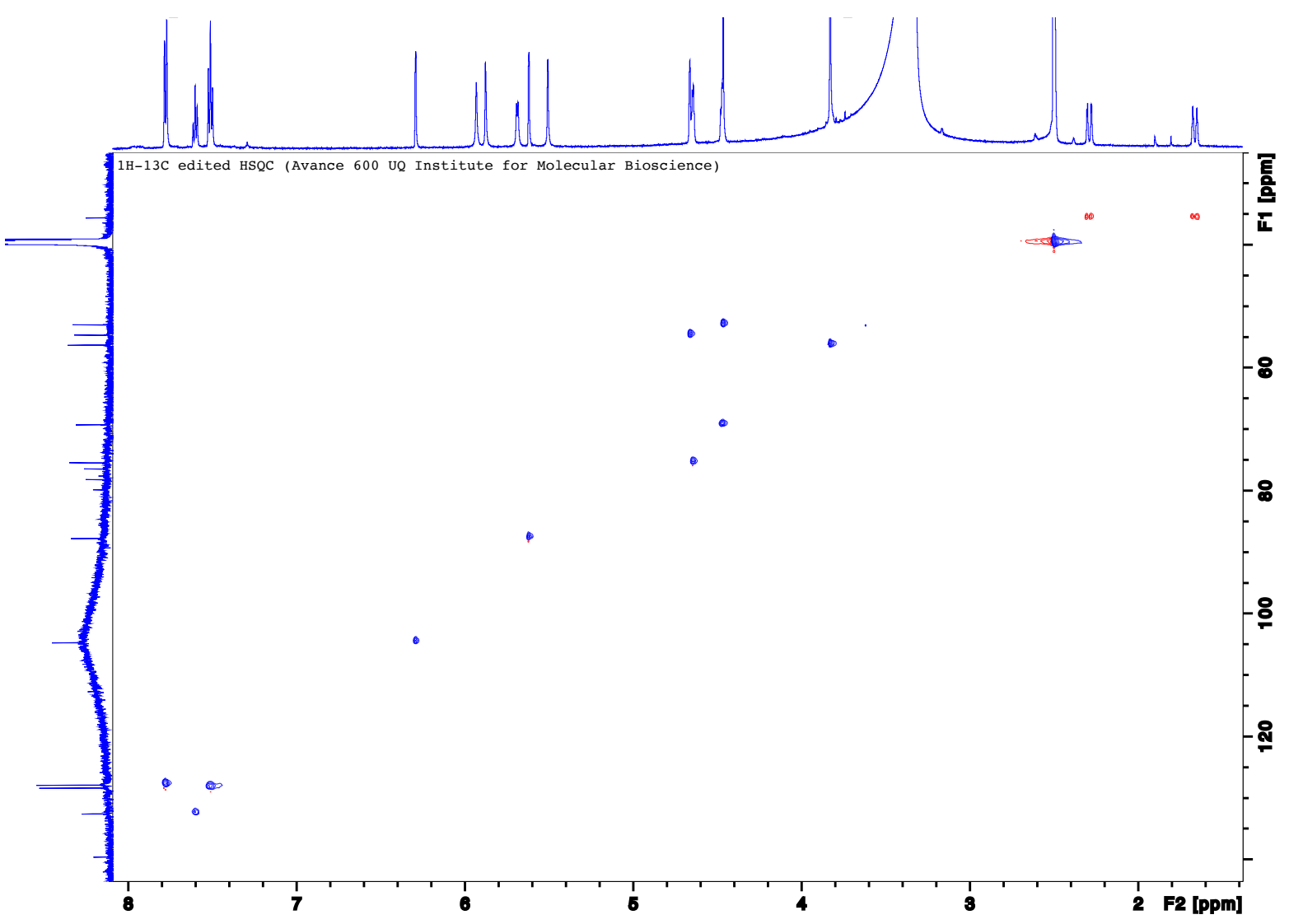

Figure S9. HSQC (600 MHz, DMSO- $\left.d_{6}\right)$ spectrum of enterocin (1).

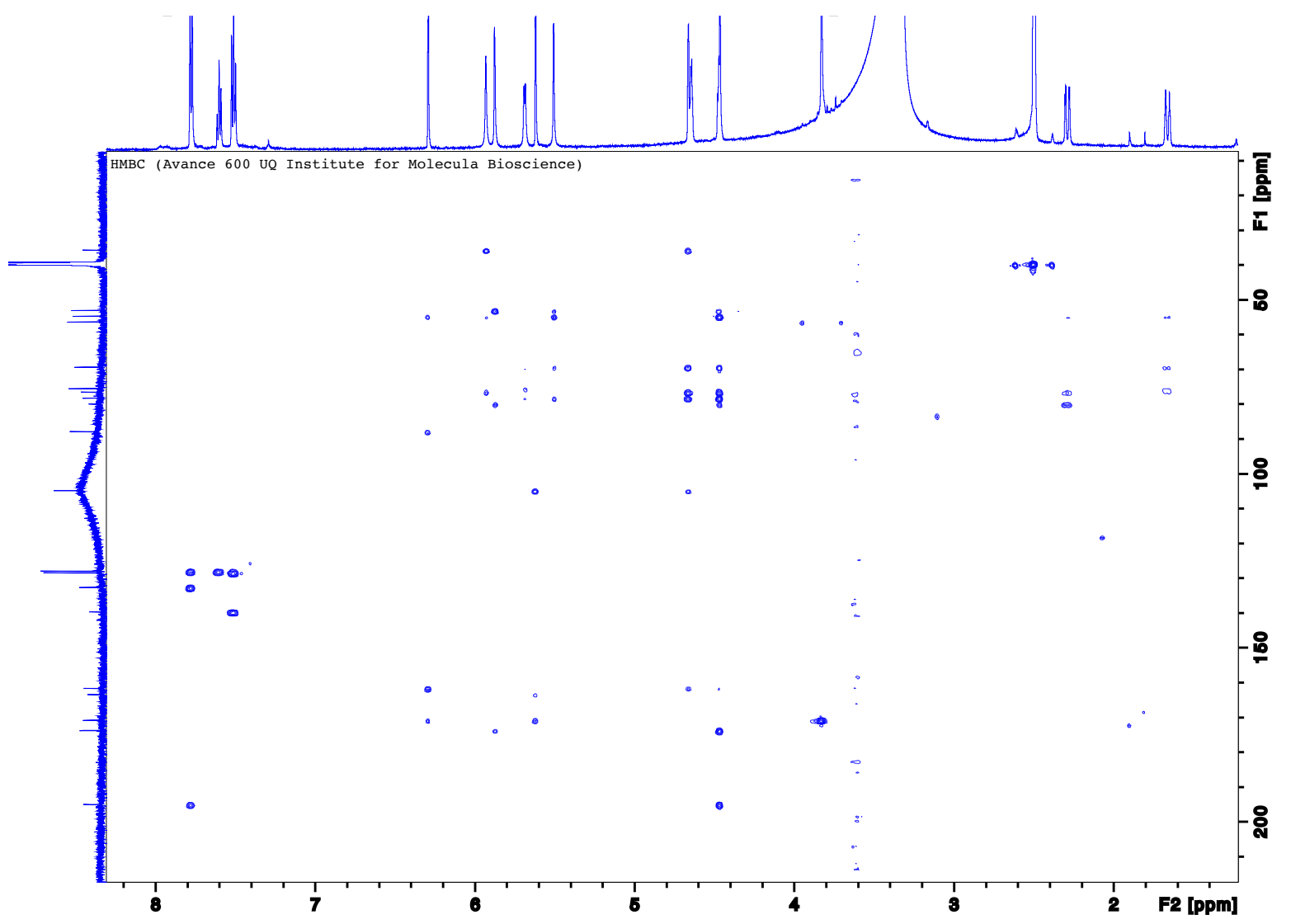

Figure S10. HMBC (600 MHz, DMSO- $\left.d_{6}\right)$ spectrum of enterocin (1). 


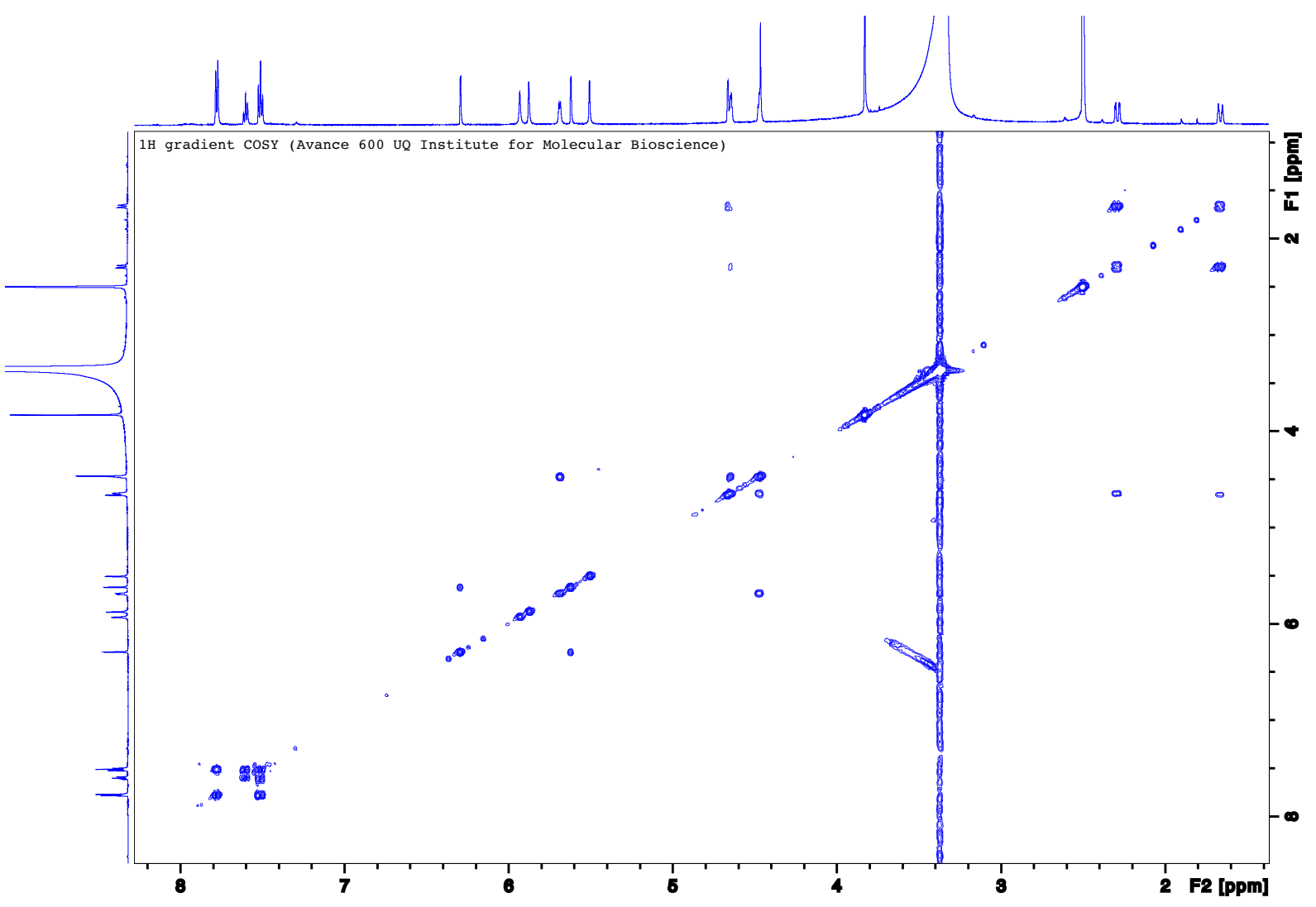

Figure S11. COSY (600 MHz, DMSO- $\left.d_{6}\right)$ spectrum of enterocin (1).

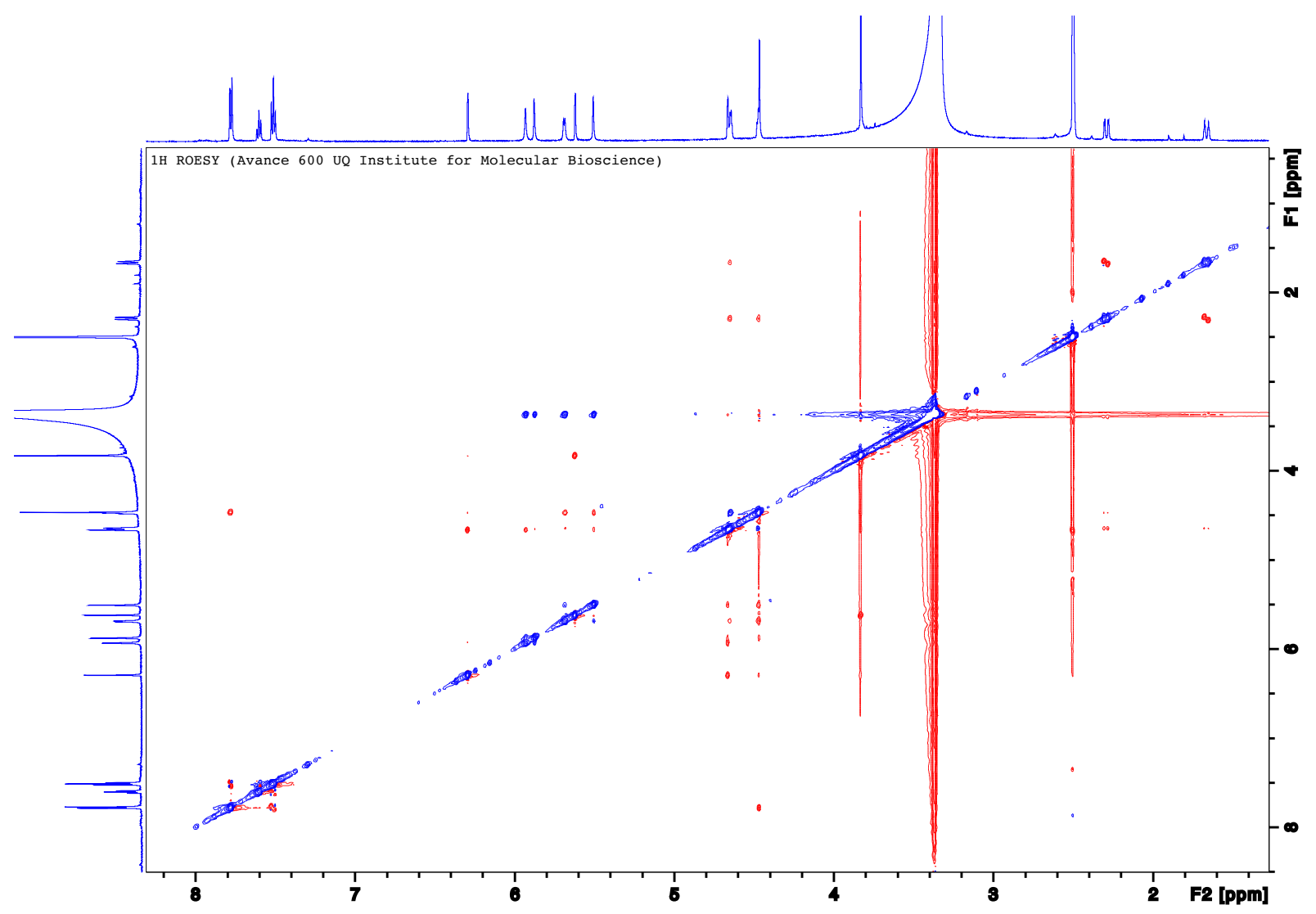

Figure S12. ROESY (600 MHz, DMSO- $\left.d_{6}\right)$ spectrum of enterocin (1). 


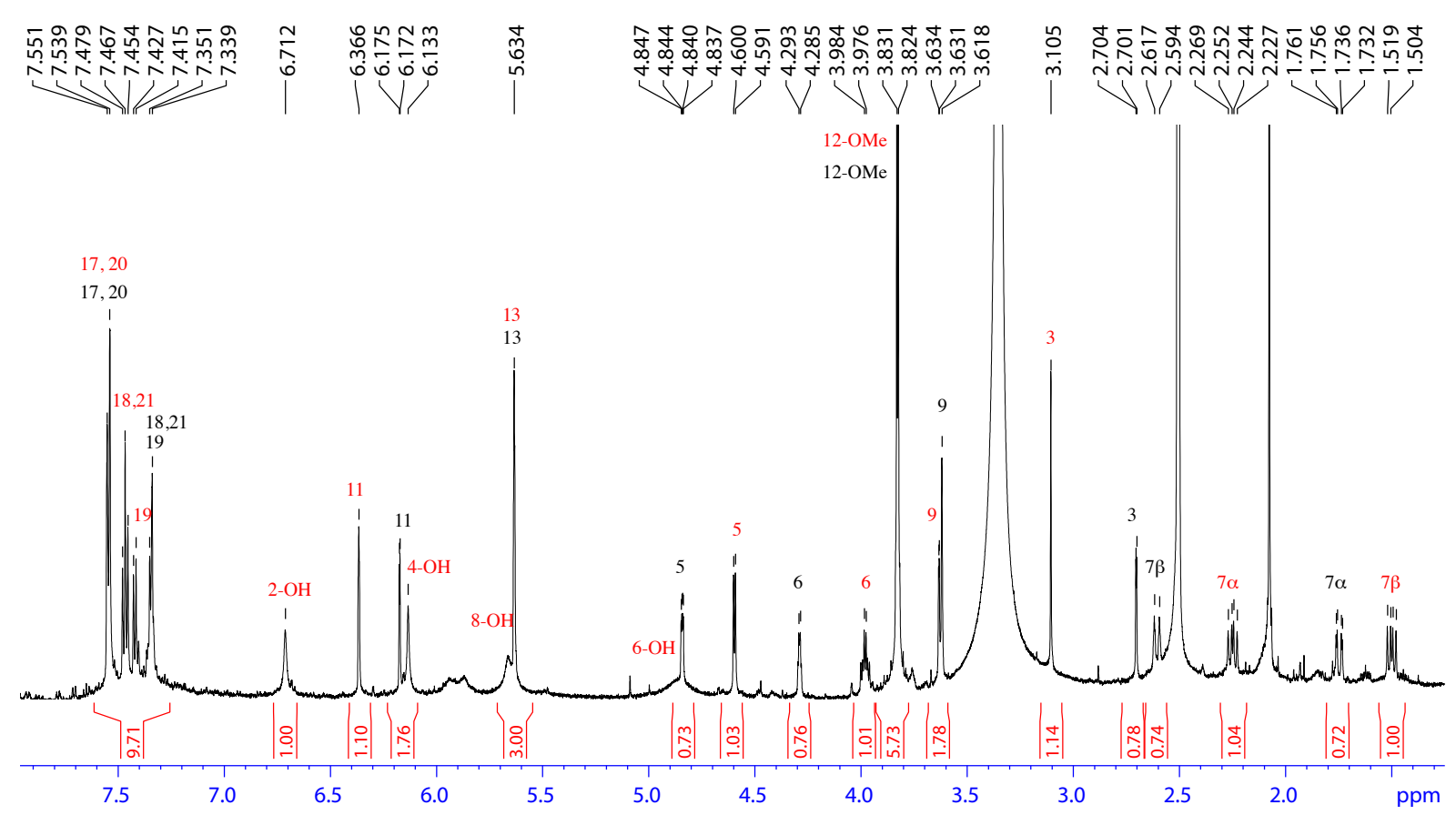

Figure S13. ${ }^{1} \mathrm{H}$ NMR (600 MHz, DMSO- $d_{6}$ ) spectrum for enterocin B (6) (black numbering) and C (7) - (red numbering).
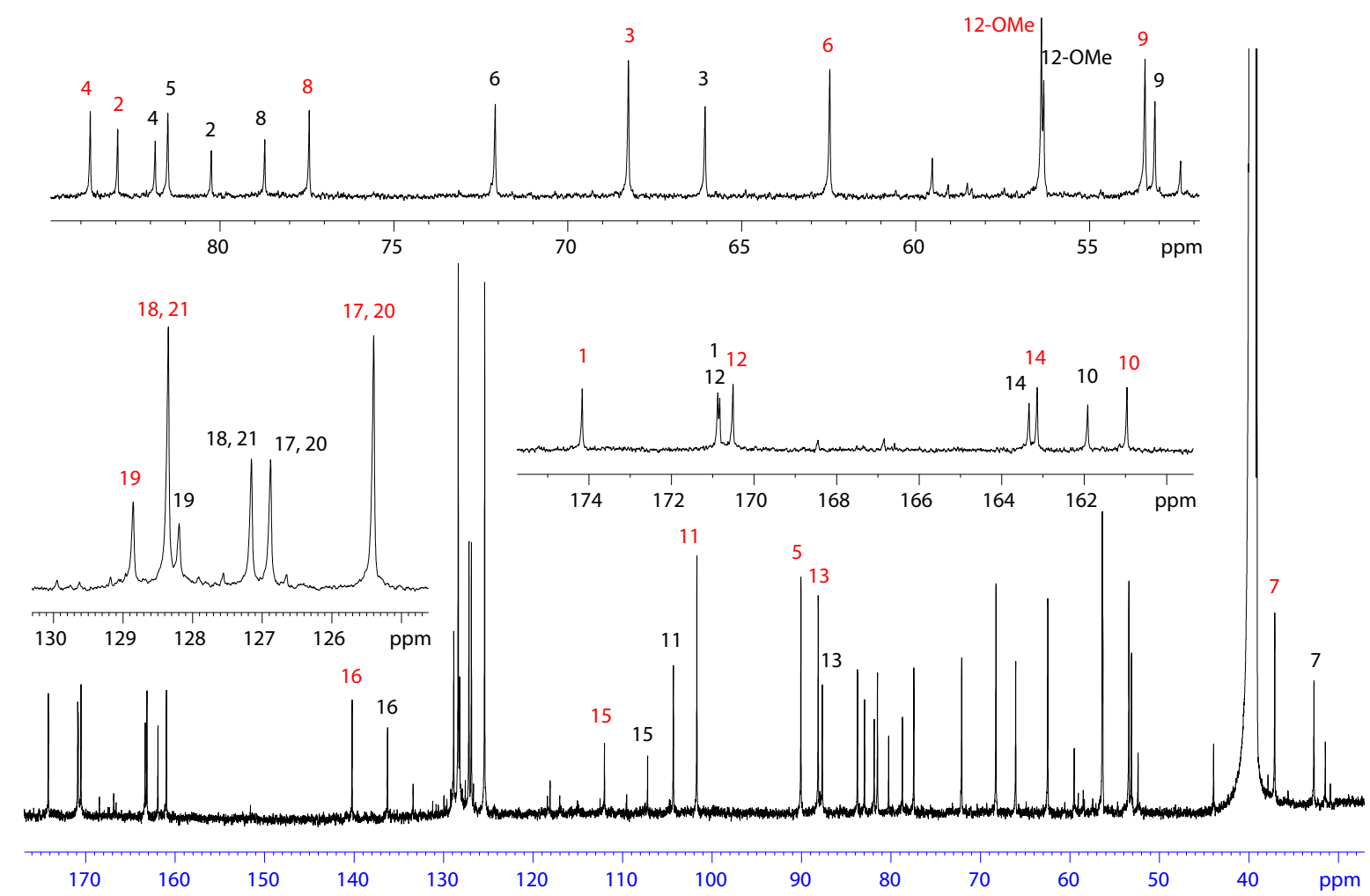

Figure S14. ${ }^{13} \mathrm{C}$ NMR (125 MHz, DMSO- $\left.d_{6}\right)$ spectrum for enterocins B (6) (black numbering) and $\mathrm{C}(7)-$ (red numbering). 


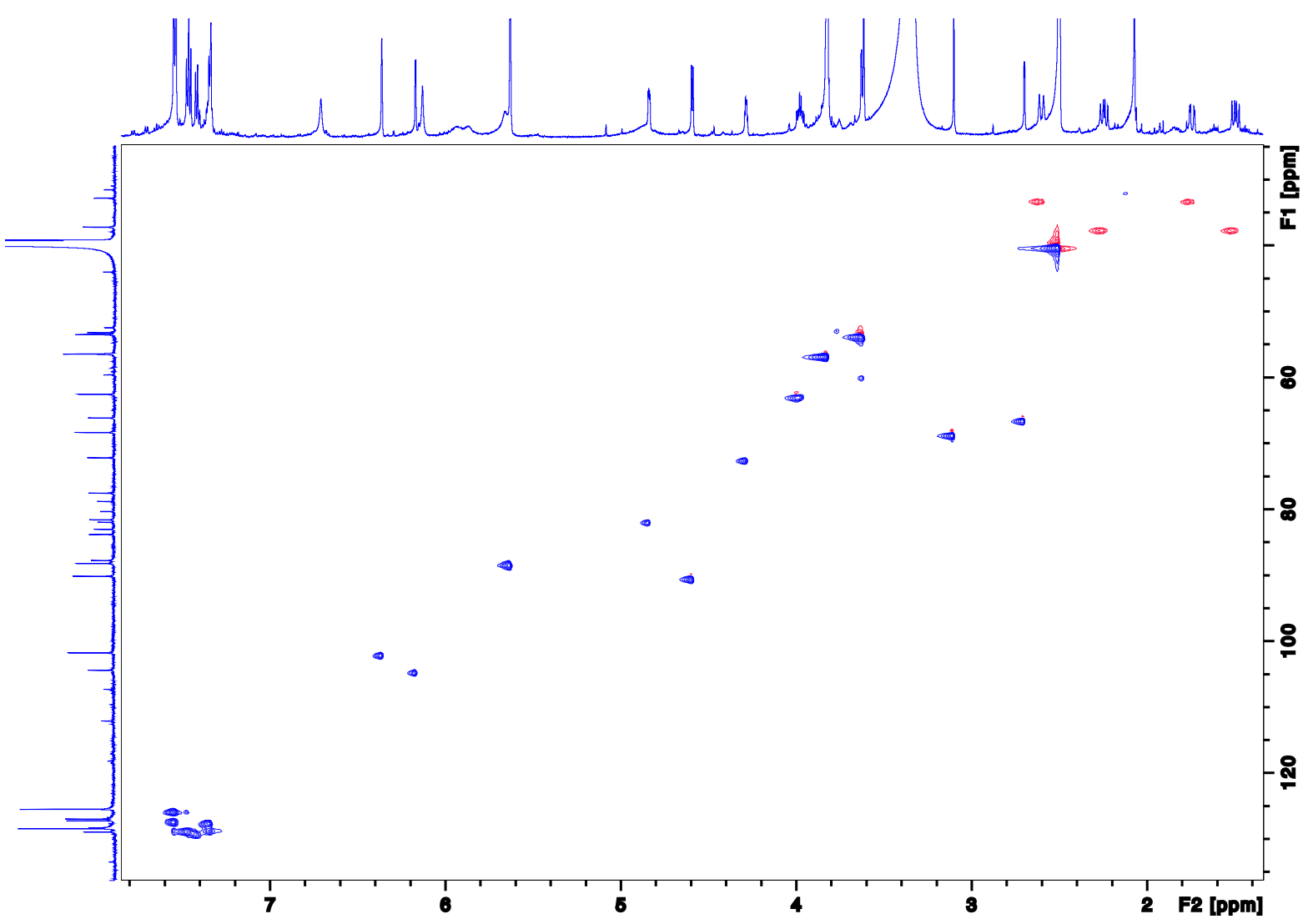

Figure S15. HSQC $\left(600 \mathrm{MHz}, \mathrm{DMSO}-d_{6}\right)$ spectrum of enterocins B (6) and C (7).

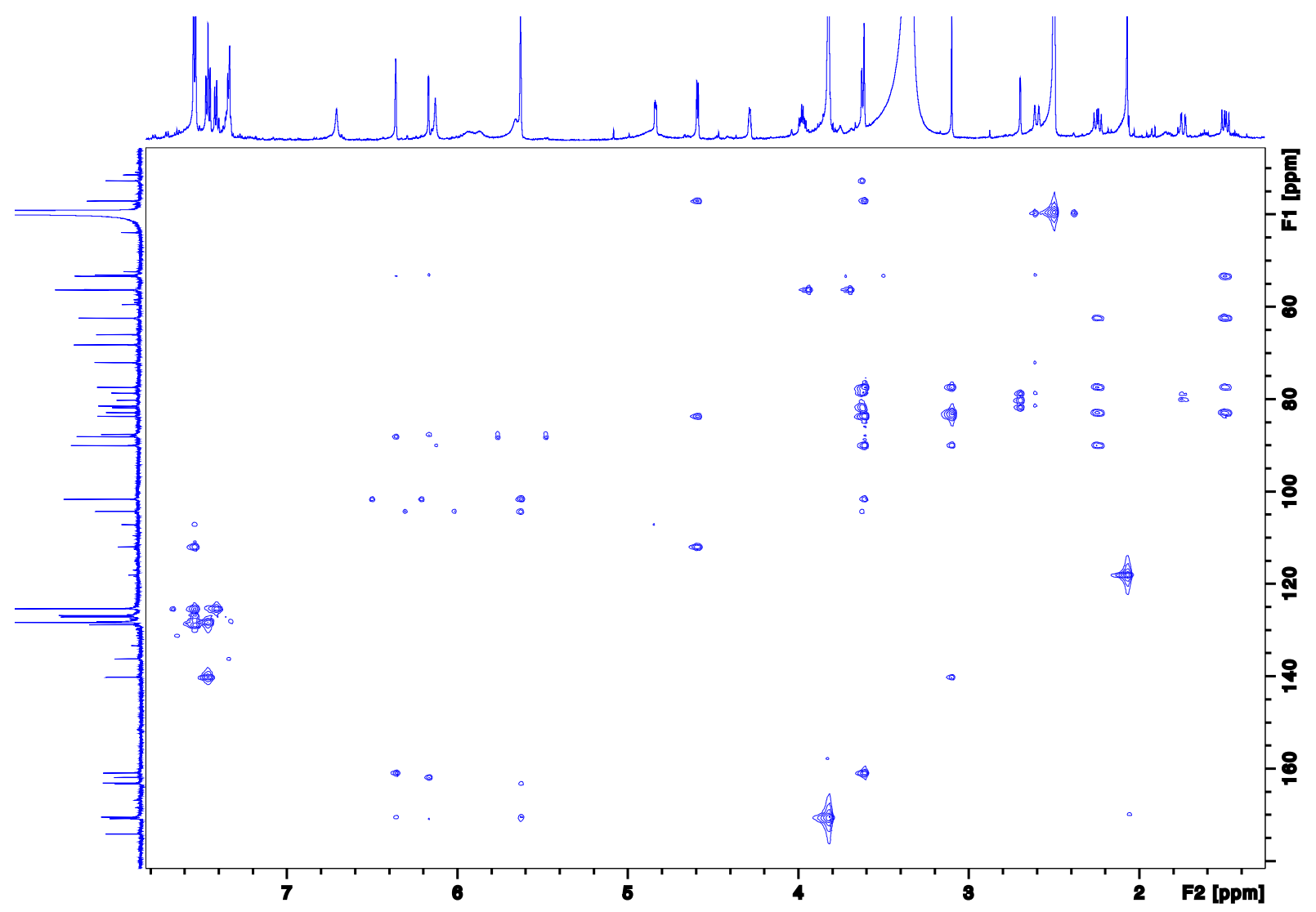

Figure S16. HMBC (600 MHz, DMSO- $\left.d_{6}\right)$ spectrum of enterocins B (6) and C (7). 


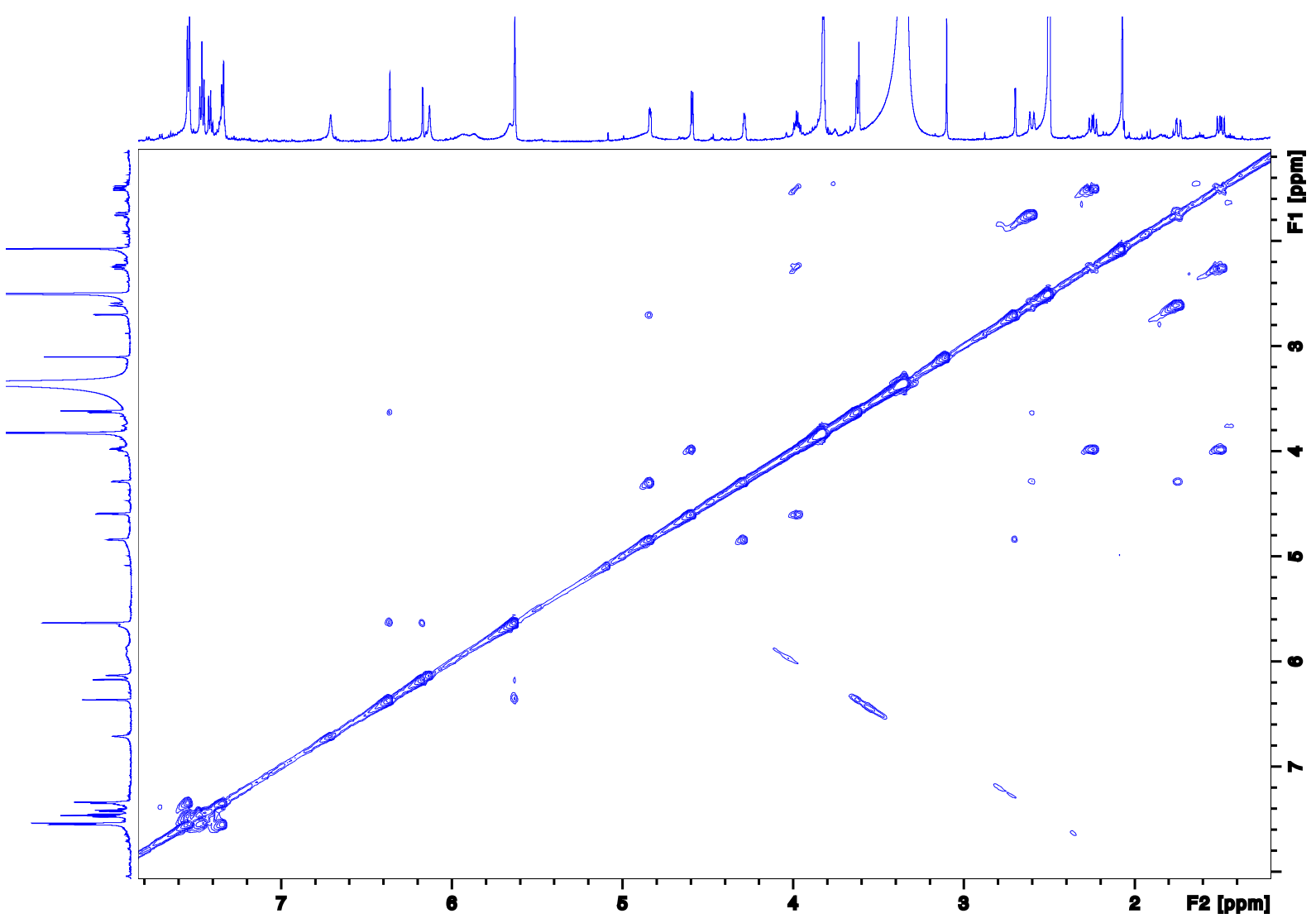

Figure S17. COSY (600 MHz, DMSO- $\left.d_{6}\right)$ spectrum of enterocins B (6) and C (7).

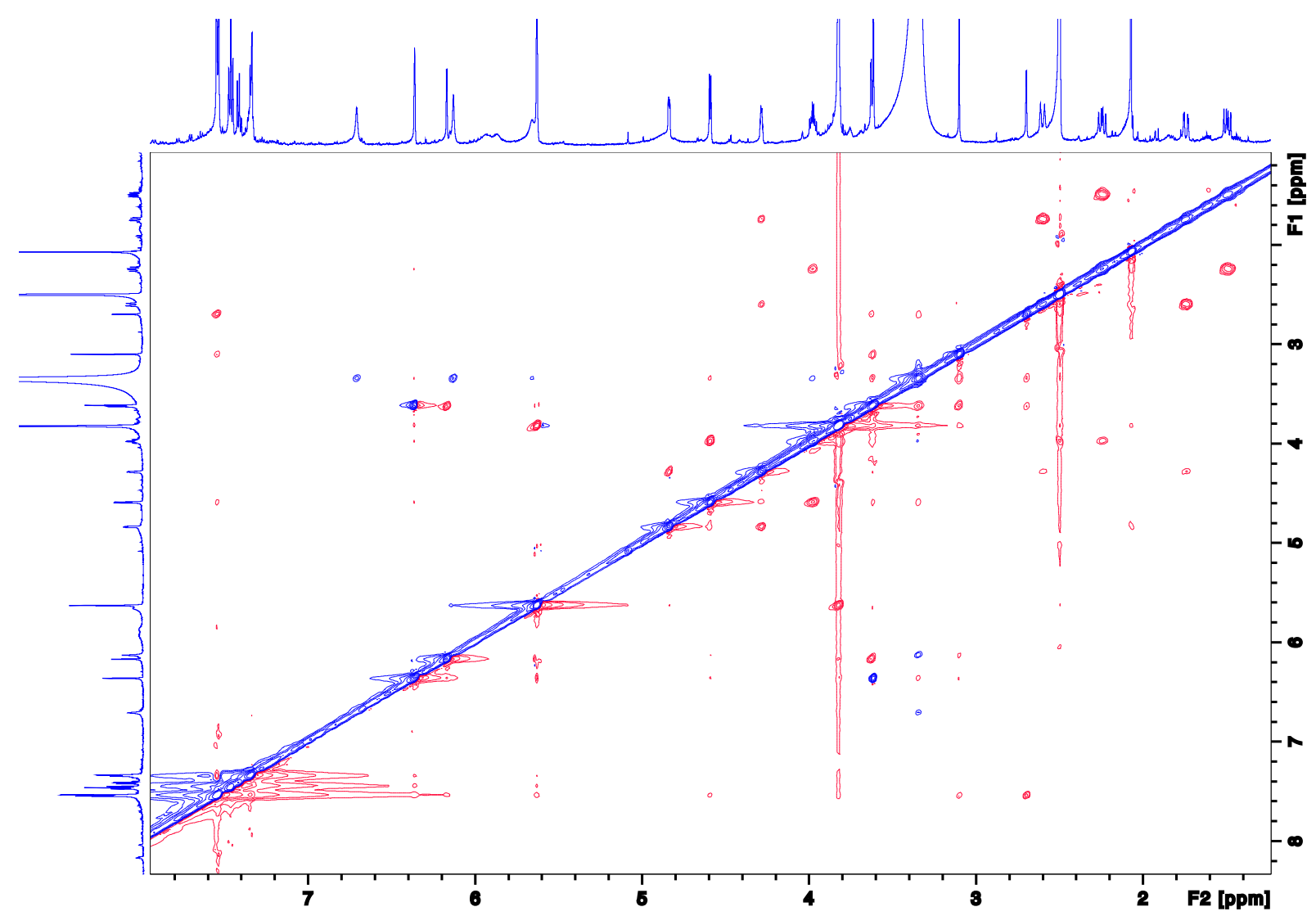

Figure S18. ROESY (600 MHz, DMSO- $d_{6}$ ) spectrum of enterocins B (6) and C (7). 


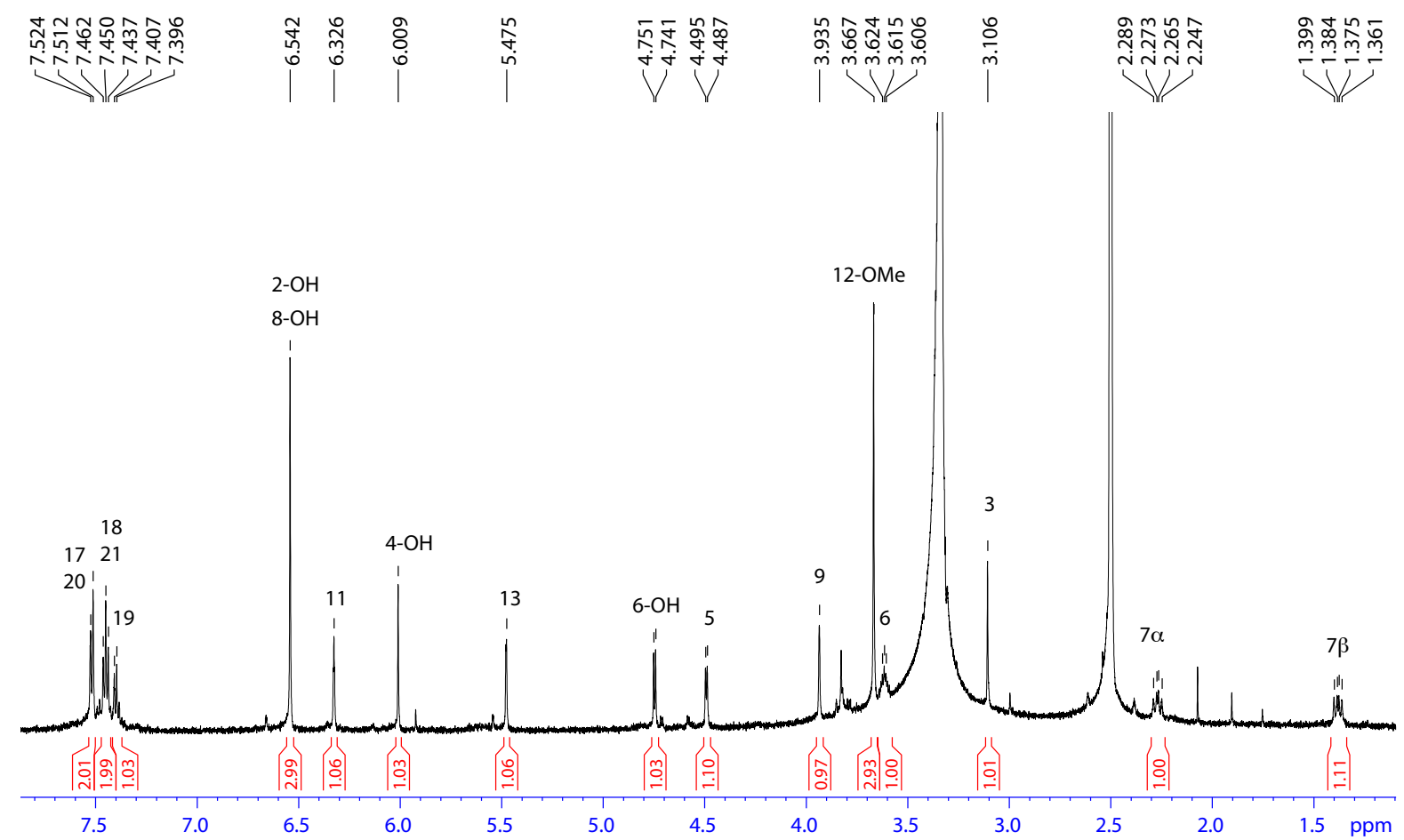

Figure S19. ${ }^{1} \mathrm{H}$ NMR $\left(600 \mathrm{MHz}, \mathrm{DMSO}-d_{6}\right)$ spectrum for enterocin D (8).

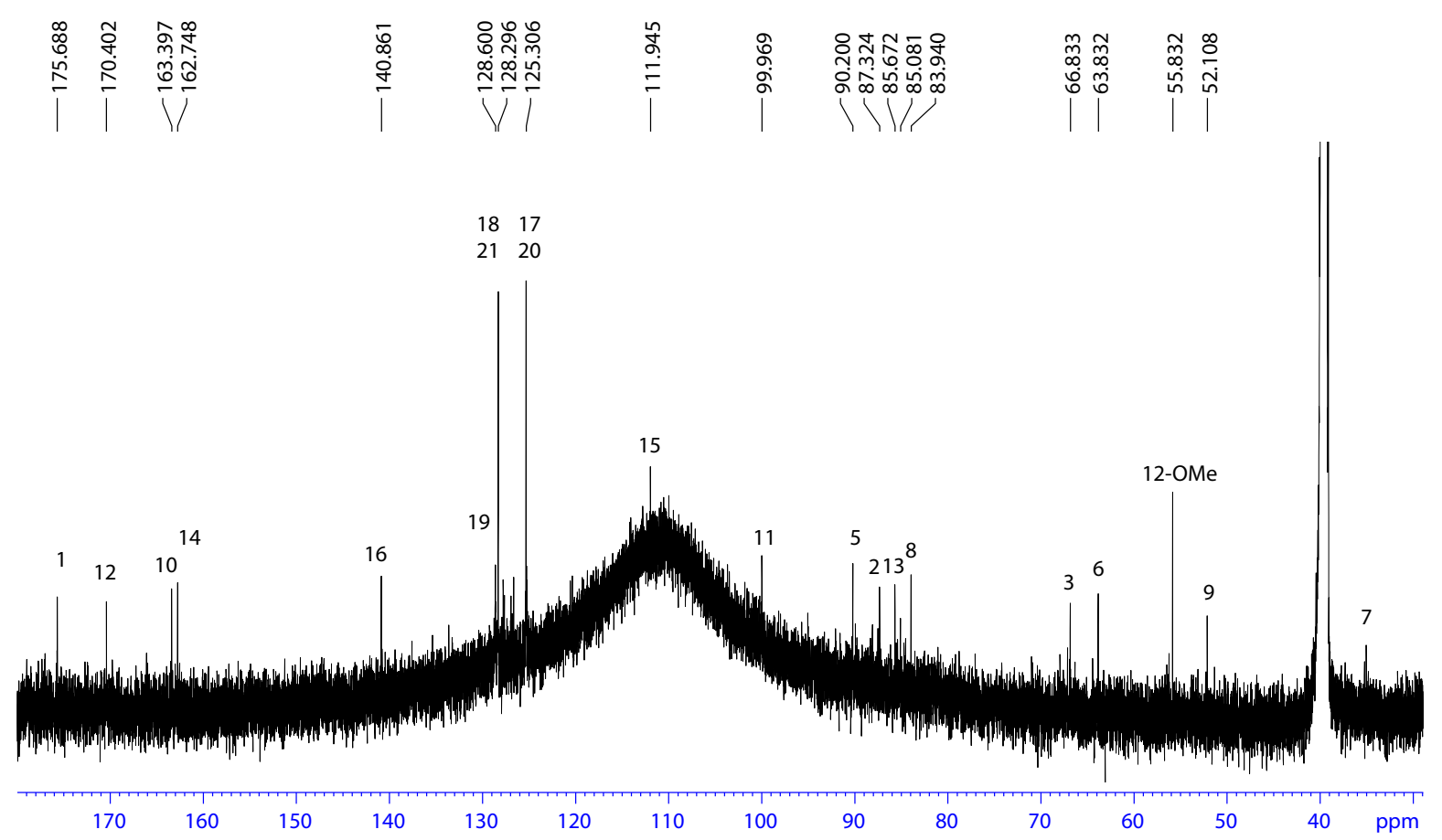

Figure S20. ${ }^{13} \mathrm{C}$ NMR (125 MHz, DMSO- $\left.d_{6}\right)$ spectrum for enterocin D (8). 


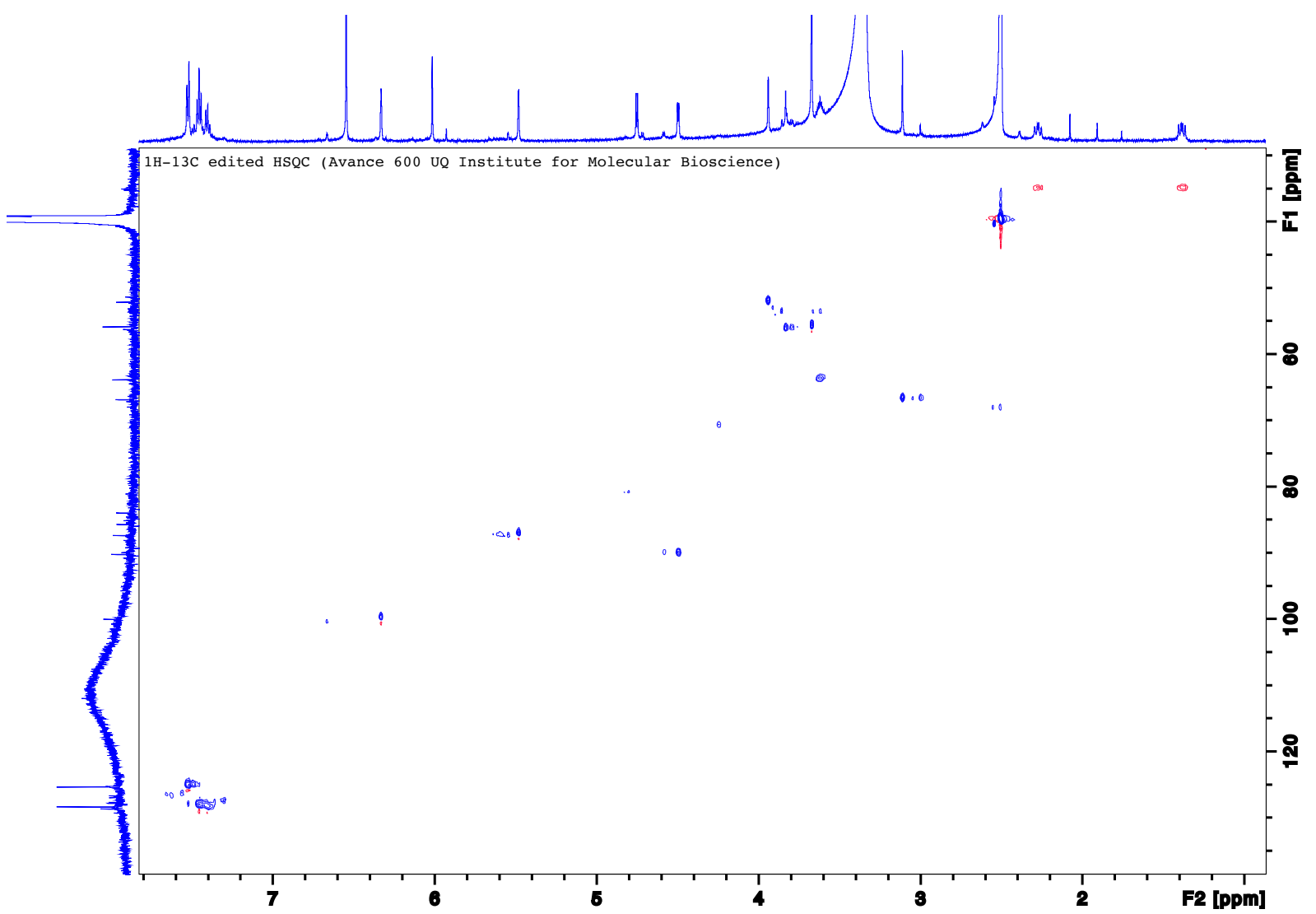

Figure S21. HSQC (600 MHz, DMSO- $\left.d_{6}\right)$ spectrum of enterocin D (8)

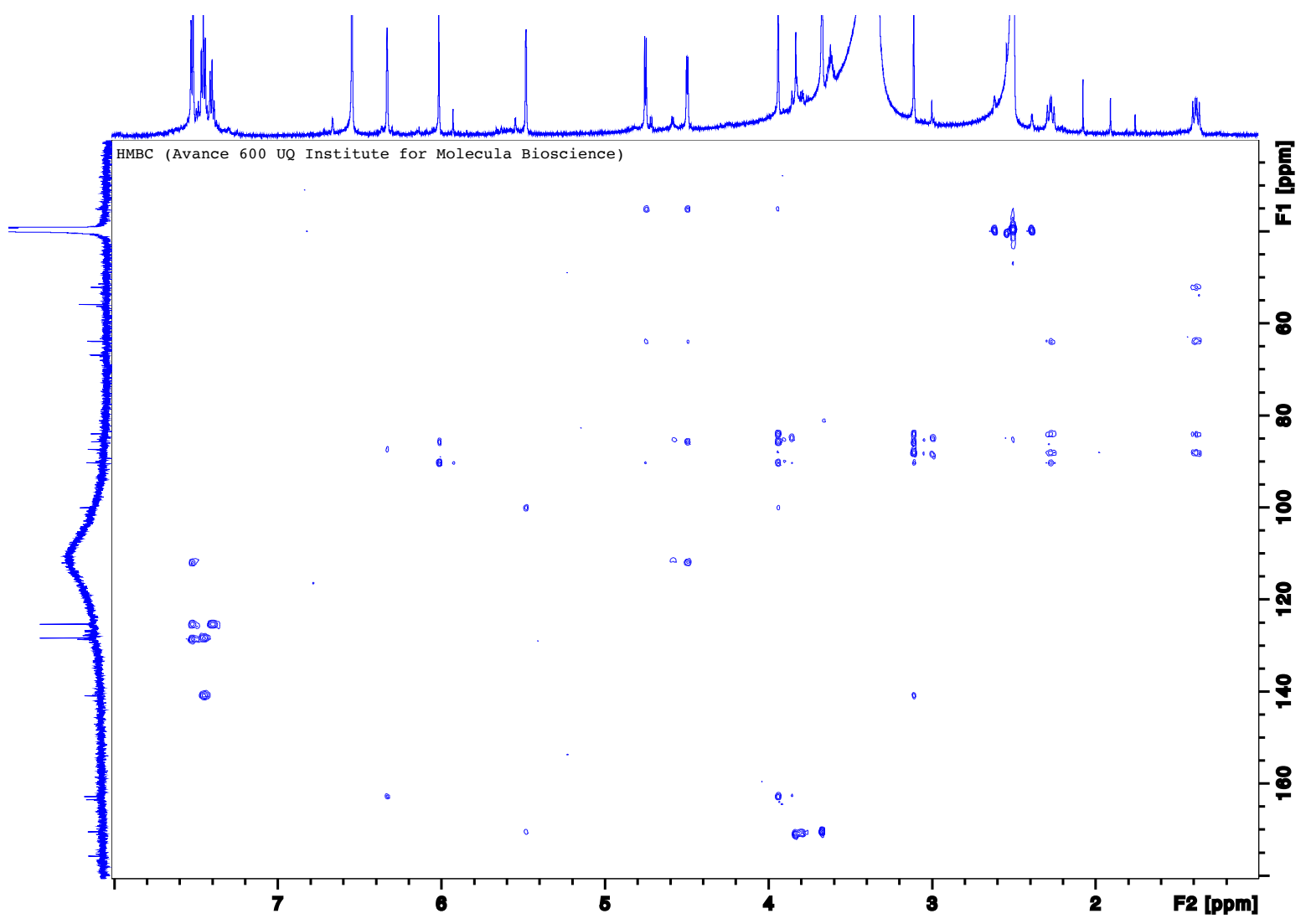

Figure S22. HMBC (600 MHz, DMSO- $\left.d_{6}\right)$ spectrum of enterocin D (8) 


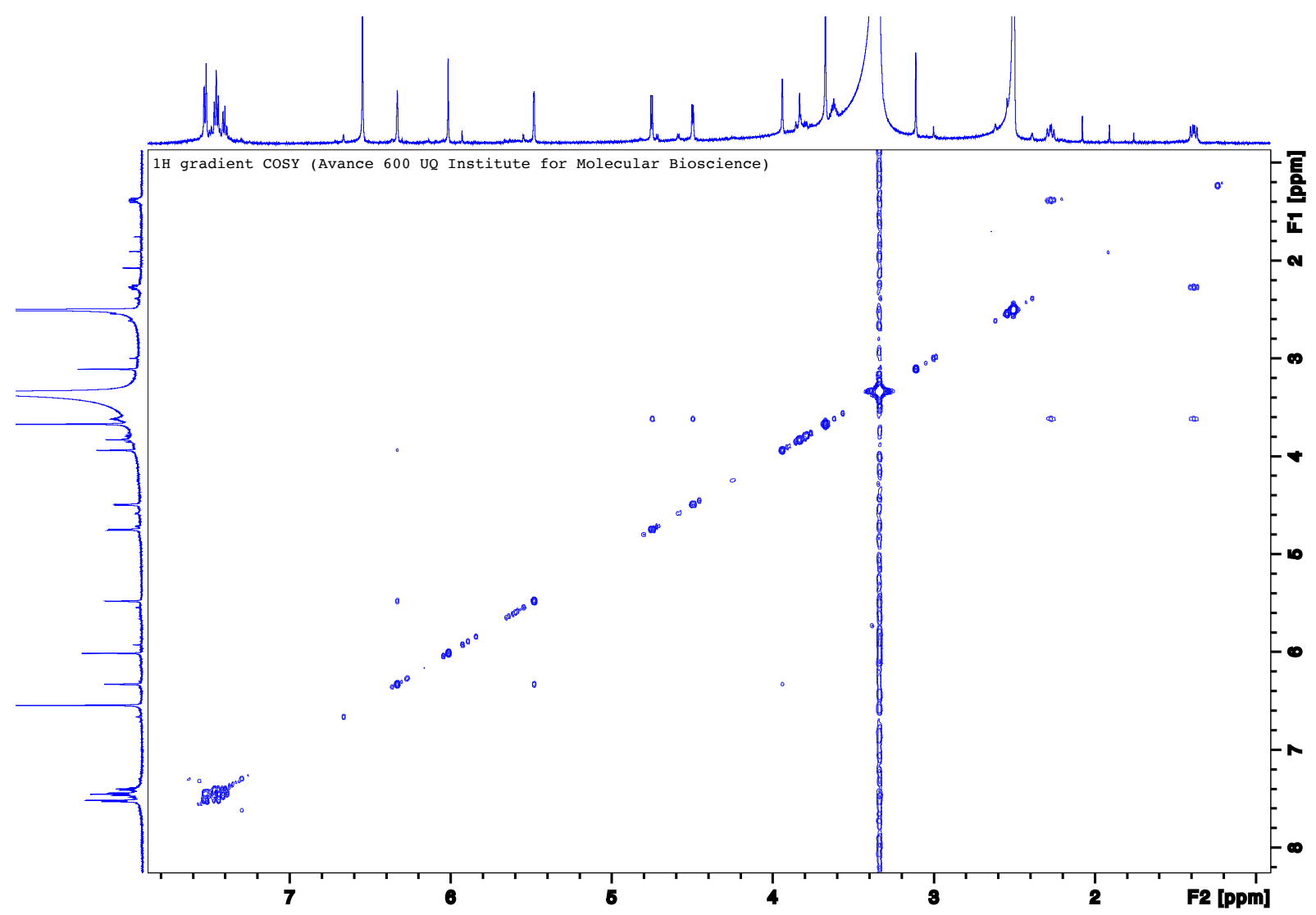

Figure S23. COSY (600 MHz, DMSO- $\left.d_{6}\right)$ spectrum of enterocin D (8)

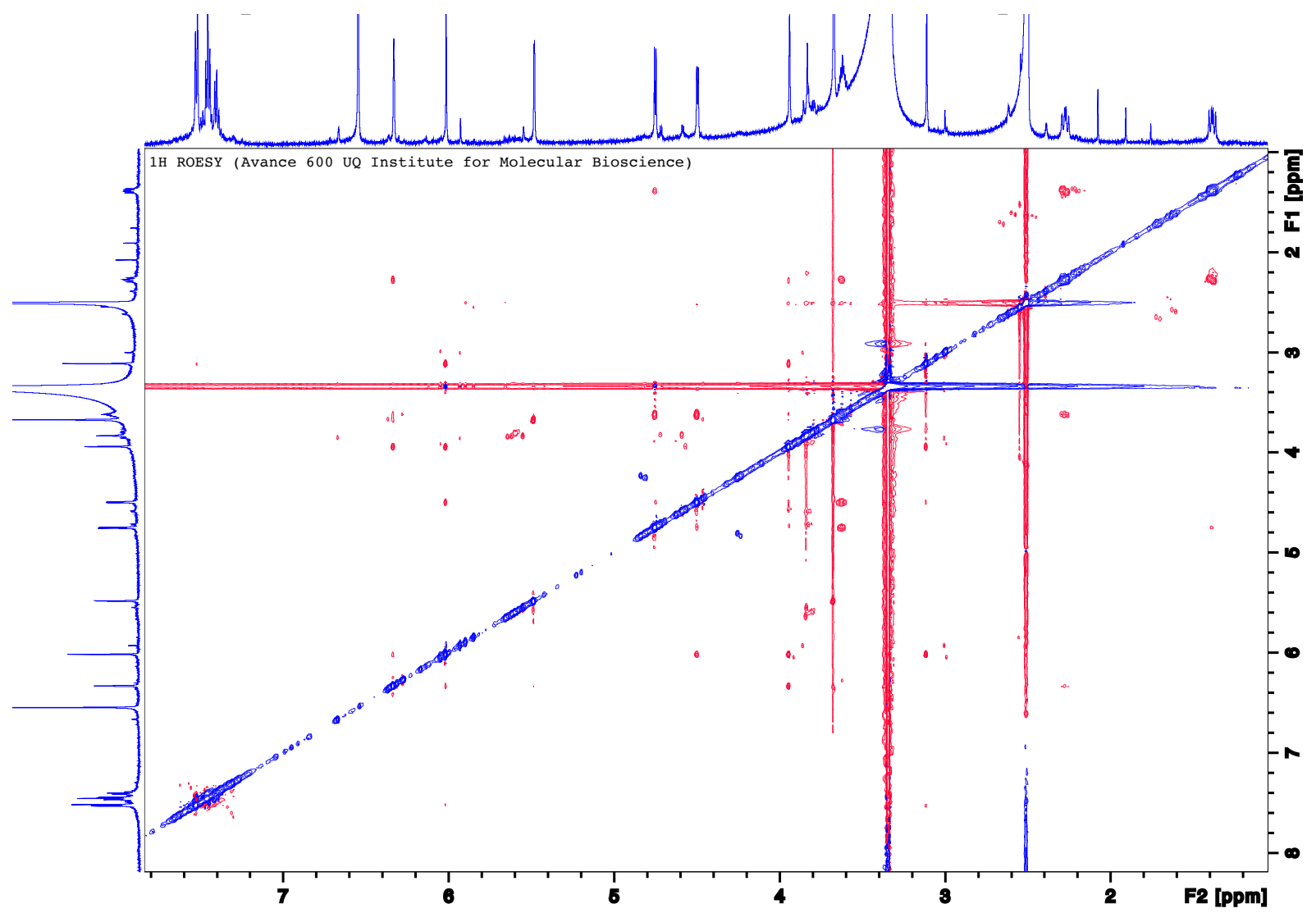

Figure S24. ROESY (600 MHz, DMSO- $\left.d_{6}\right)$ spectrum of enterocin D (8) 


\section{HPLC study of enterocin transformation}
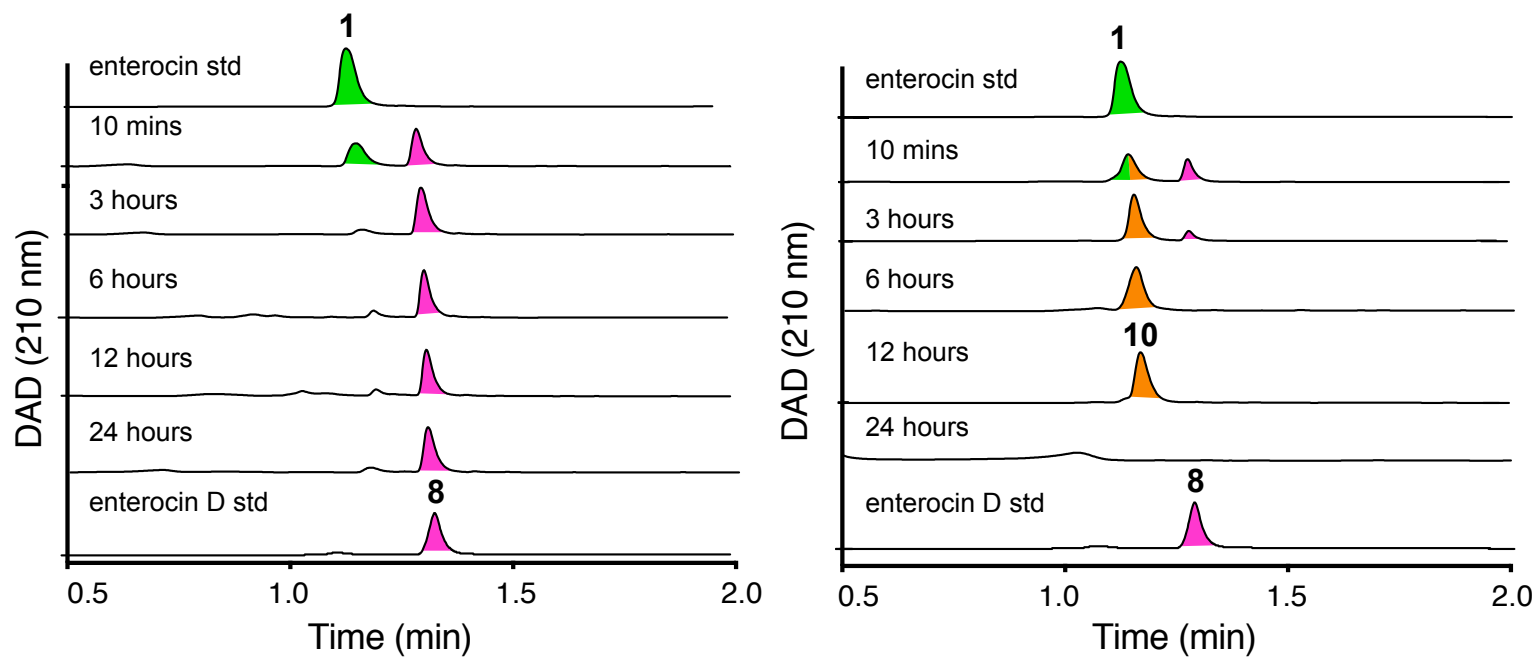

Figure S25. UPLC chromatogram of enterocin at $\mathrm{pH} 11$ (adjusted with TEA) at r.t. at different time point in $100 \% \mathrm{MeCN}$ (left) and in $\mathrm{MeCN} / \mathrm{H}_{2} \mathrm{O} 1: 1$ ratio (right).

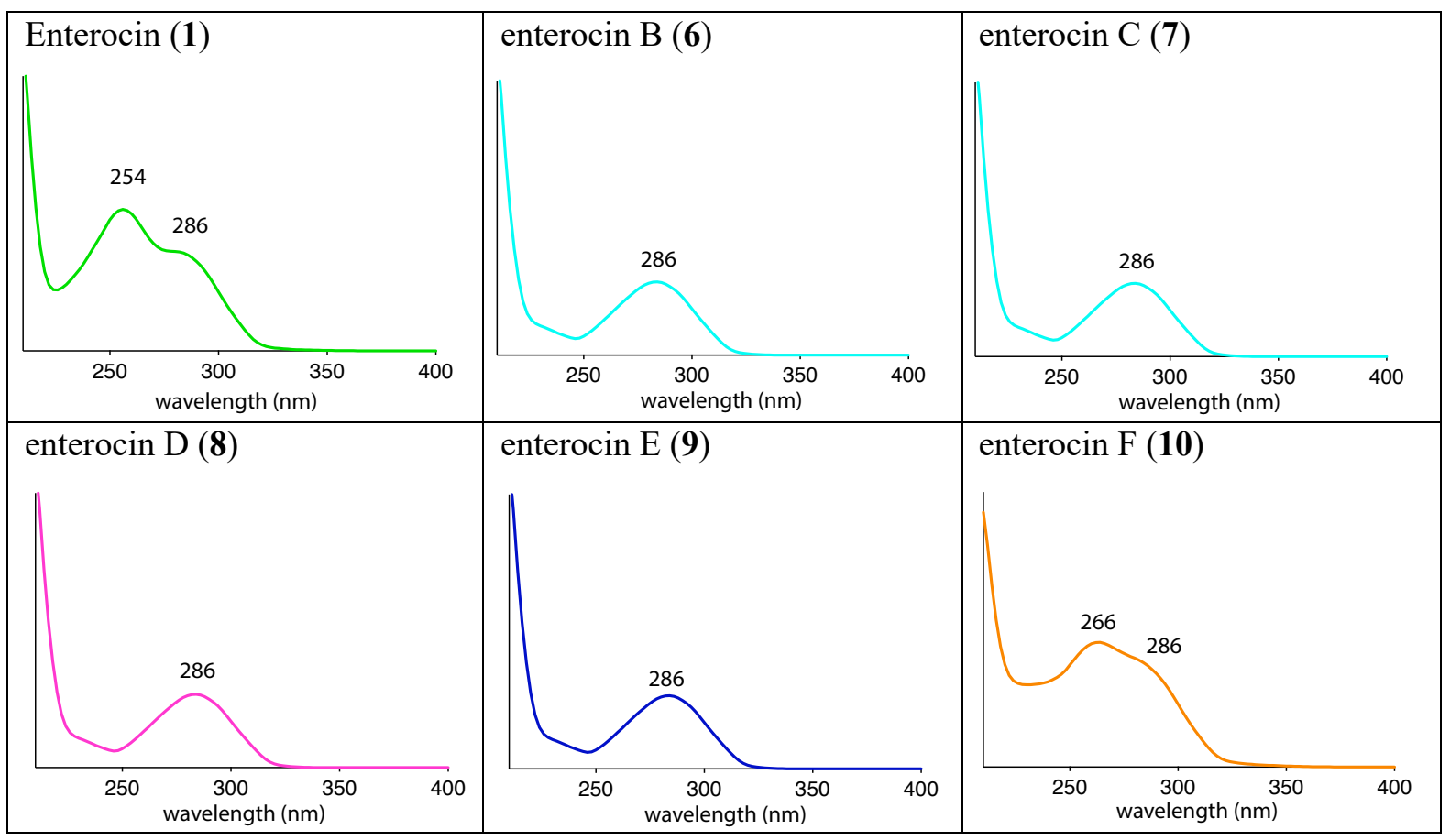

Figure S26. UV spectra of enterocin and its analogs 


\section{Antibacterial assay in normal nutrient media.}

The bacterium to be tested was streaked onto a LB agar plate and was incubated at 37 ${ }^{\circ} \mathrm{C}$ for $24 \mathrm{~h}$. One colony was then transferred to fresh LB broth $(5 \mathrm{~mL})$ and the cell density was adjusted to $10^{4}-10^{5} \mathrm{CFU} / \mathrm{mL}$. The compounds to be tested were dissolved in DMSO and diluted with $\mathrm{H}_{2} \mathrm{O}$ to give $1200 \mu \mathrm{M}$ stock solution (20\% DMSO), which was serially diluted with $20 \%$ DMSO to give concentrations from $1200 \mu \mathrm{M}$ to $0.4 \mu \mathrm{M}$ in $20 \%$ DMSO. An aliquot $(10 \mu \mathrm{L})$ of each dilution was transferred to a 96-well microtiter plate and freshly prepared microbial broth $(190 \mu \mathrm{L})$ was added to each well to give final concentrations of $60-0.02 \mu \mathrm{M}$ in $1 \%$ DMSO. The plates were incubated at $37^{\circ} \mathrm{C}$ for $24 \mathrm{~h}$ and the optical density of each well was measured spectrophotometrically at $600 \mathrm{~nm}$ using POLARstar Omega plate (BMG LABTECH, Offenburg, Germany). Each test compound was screened against the susceptible Gramnegative bacterium Escherichia coli ATCC11775 and the Gram-positive bacteria Staphylococcus aureus ATCC 25923, Bacillus subtilis ATCC6633 and multi-drug resistant (MDR) vancomycin-resistant Enterococcus faecalis (AUS-RBWH-VRE-01). Rifampicin was used as a positive control (30 $\mu \mathrm{M}$ in $1 \% \mathrm{DMSO})$ for the susceptible strains, while vancomycin was used as control (30 $\mu \mathrm{M}$ in 1\% DMSO) for the MDR strain. DMSO $1 \%$ served as negative control. Enterocin (1) did not show any activity when tested at max concentration of $60 \mu \mathrm{M}$ against all bacteria.
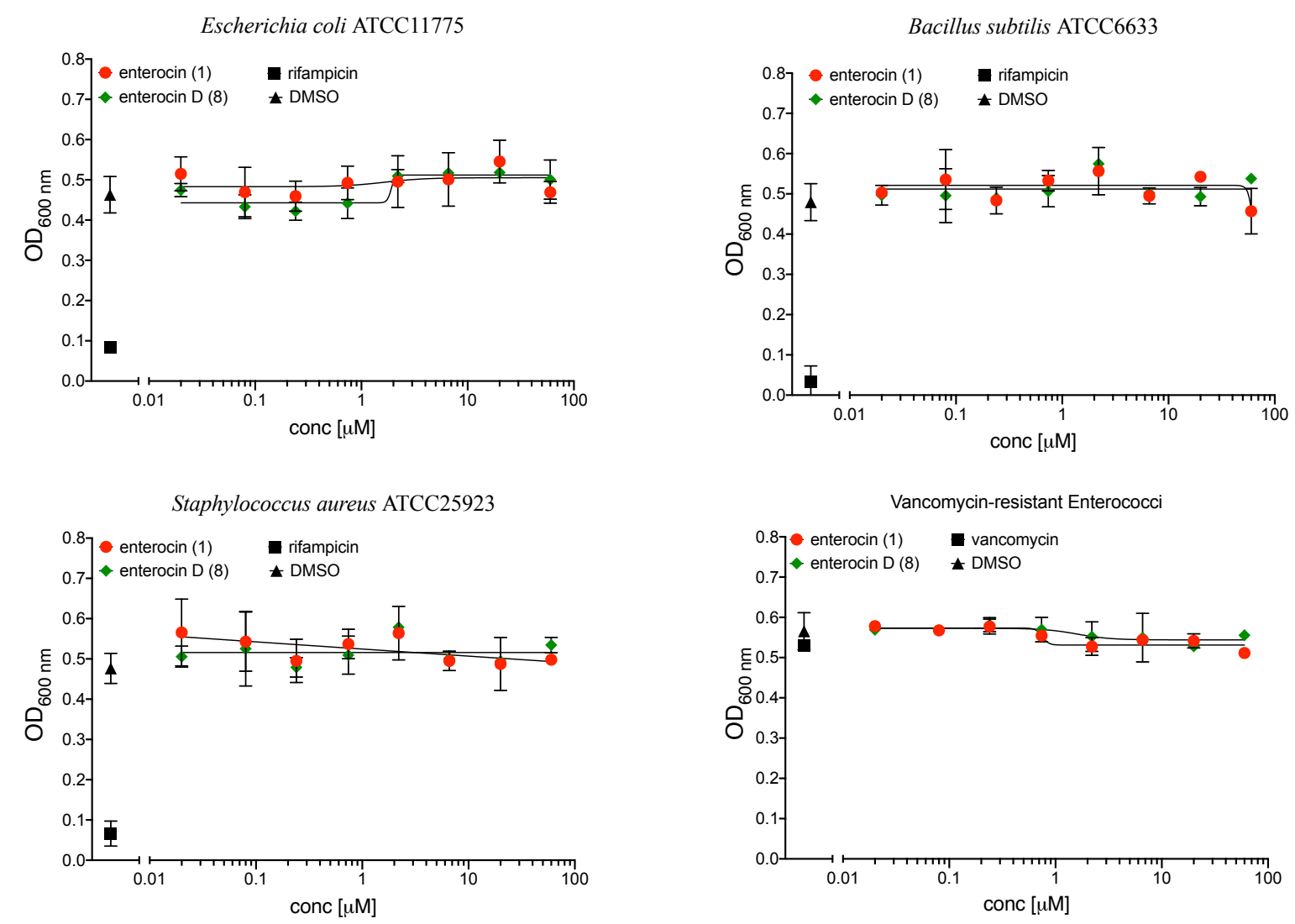

Figure S27. Antibacterial results for $\mathbf{1}$ and $\mathbf{8}$ against selected bacteria in the normal nutrient media 


\section{Antibacterial assay in minimal media}

This protocol was performed according to the method described by Thakur et al. (Appl Microbiol Biotechnol, 2010, 88, 771-779) with slight modifications. The antibacterial properties of enterocin (1) and enterocin D (8) were evaluated using E. coli ATCC11775 Briefly, the bacterium to be tested was streaked onto a LB agar plate and was incubated at 37 ${ }^{\circ} \mathrm{C}$ for $24 \mathrm{~h}$. One colony was then transferred to fresh minimal media $(5 \mathrm{~mL})$ and grown overnight at $37{ }^{\circ} \mathrm{C}$. The $5 \mathrm{x}$ media was prepared as follows: $\mathrm{Na}_{2} \mathrm{HPO}_{4} .7 \mathrm{H}_{2} \mathrm{O}(64 \mathrm{~g}), \mathrm{KH}_{2} \mathrm{PO}_{4}$ $(15 \mathrm{~g}), \mathrm{NaCl}(2.5 \mathrm{~g}), \mathrm{NH}_{4} \mathrm{Cl}(5 \mathrm{~g})$ were dissolved in $1 \mathrm{~L}$ of distilled water and sterilized at 121 ${ }^{\circ} \mathrm{C}$ for $15 \mathrm{~min}$. An aliquot $200 \mathrm{~mL}$ of this media was supplemented with filter sterilized glucose $(20 \%), \mathrm{MgSO}_{4}(1 \mathrm{M}), \mathrm{CaCl}_{2}(1 \mathrm{M})$, Thiamine $(0.5 \% \mathrm{w} / \mathrm{v})$ then the volume was adjusted to $1 \mathrm{~L}$ with sterile distilled water. The overnight culture was pelleted at $3,000 \mathrm{rpm}$ at $4{ }^{\circ} \mathrm{C}$ for $5 \mathrm{~min}$, the pellets were washed twice with 1x PBS and gently suspended in $10 \mathrm{~mL}$ of M9 minimal media. The cell density was adjusted to $10^{4}-10^{5} \mathrm{CFU} / \mathrm{mL}(\sim \mathrm{OD} 0.05)$. An aliquot (190 $\left.\mu \mathrm{L}\right)$ was transferred to a 96-well microtiter plate. Enterocin (1) was dissolved in DMSO and diluted with $\mathrm{H}_{2} \mathrm{O}$ to give $20 \mathrm{mM}$ stock solution (20\% DMSO), which was serially diluted with $20 \%$ DMSO to give concentrations from $20 \mathrm{mM}$ to $9 \mu \mathrm{M}$ in $20 \%$ DMSO. Enterocin D (8) was dissolved in DMSO and diluted with $\mathrm{H}_{2} \mathrm{O}$ to give $6 \mathrm{mM}$ stock solution (20\% DMSO), which was serially diluted with $20 \%$ DMSO to give concentrations from $6 \mathrm{mM}$ to $2.6 \mu \mathrm{M}$ in $20 \%$ DMSO. An aliquot $(10 \mu \mathrm{L})$ of each dilution was added to a 96 -well microtiter containing the freshly prepared $E$. coli ATCC 11775 broth $(190 \mu \mathrm{L})$ to give final concentrations of $1000-0.45$ $\mu \mathrm{M}$ in $1 \%$ DMSO for enterocin (1) and $300-0.13 \mu \mathrm{M}$ in $1 \%$ DMSO for enterocin D (8). Penicillin $\mathrm{G}$ was used a positive control and tested at final concentration of $24-0.01 \mu \mathrm{M}$. DMSO (1\%) served as negative control. The plates were incubated at $37{ }^{\circ} \mathrm{C}$ for $24 \mathrm{~h}$ and the optical density of each well was measured spectrophotometrically at $600 \mathrm{~nm}$ using POLARstar Omega plate (BMG LABTECH, Offenburg, Germany). 

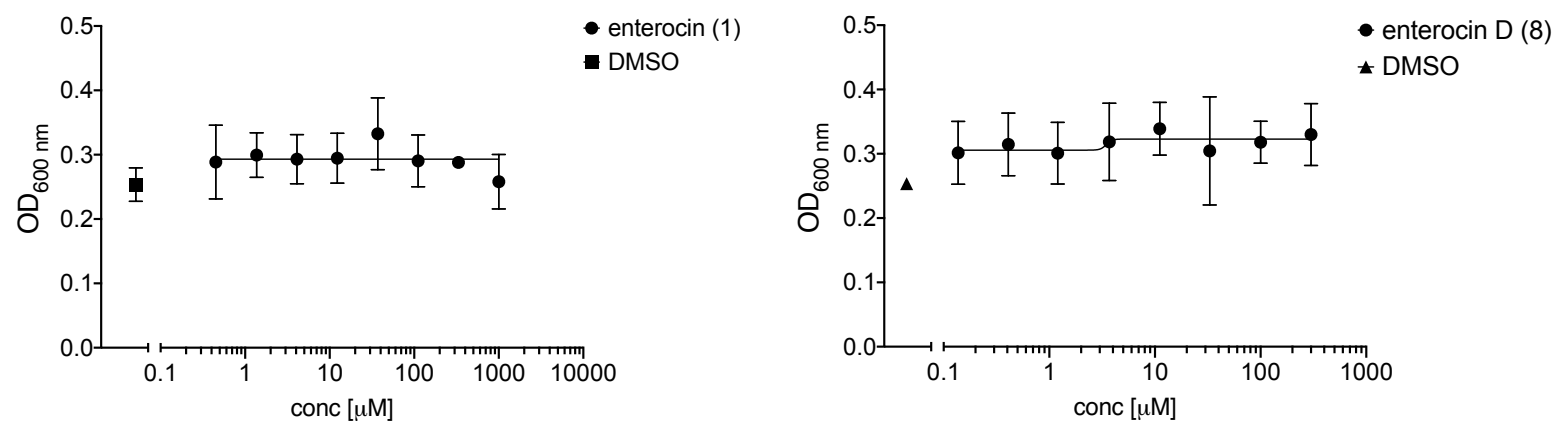

Escherichia coli ATCC11775 in M9 media

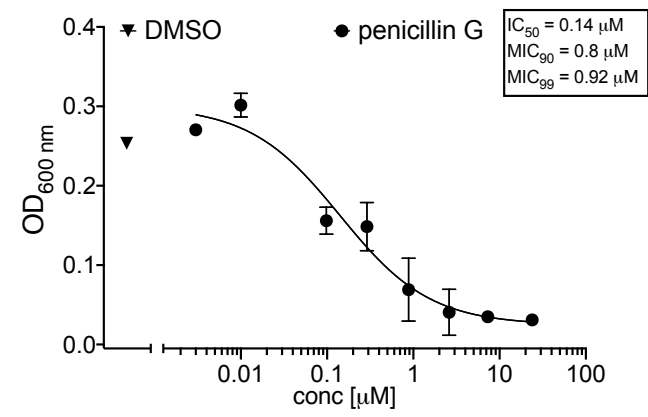

Figure S28. Antibacterial results for 1, 8 and penicillin $\mathrm{G}$ (positive control) against E. coli in the minimal media 


\section{$7 \quad$ HRMS spectra}

\section{Mass Spectrum Molecular Formula Report}

\section{Analysis Info}

Analysis Name

Method

Sample Name

Comment
Acquisition Date $\quad 1 / 31 / 2020$ 10:48:54 AM

D:IDatala.salimlenterocin A.d

tune-med AP.m
Operator

Instrument / Ser\# micrOTOF 213750.00 232
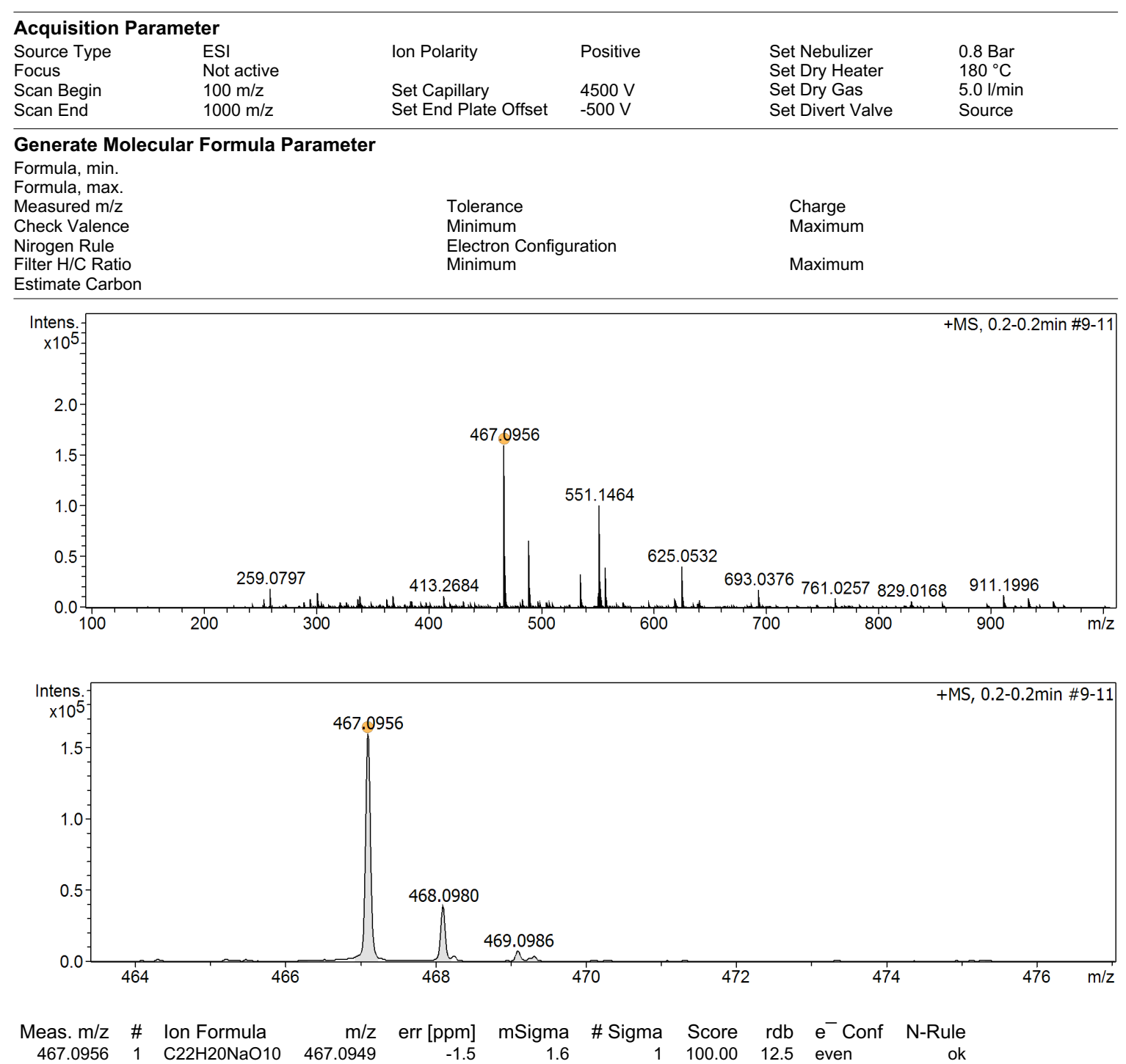

Figure S29. HRESIMS spectrum and measurement for enterocin (1). 


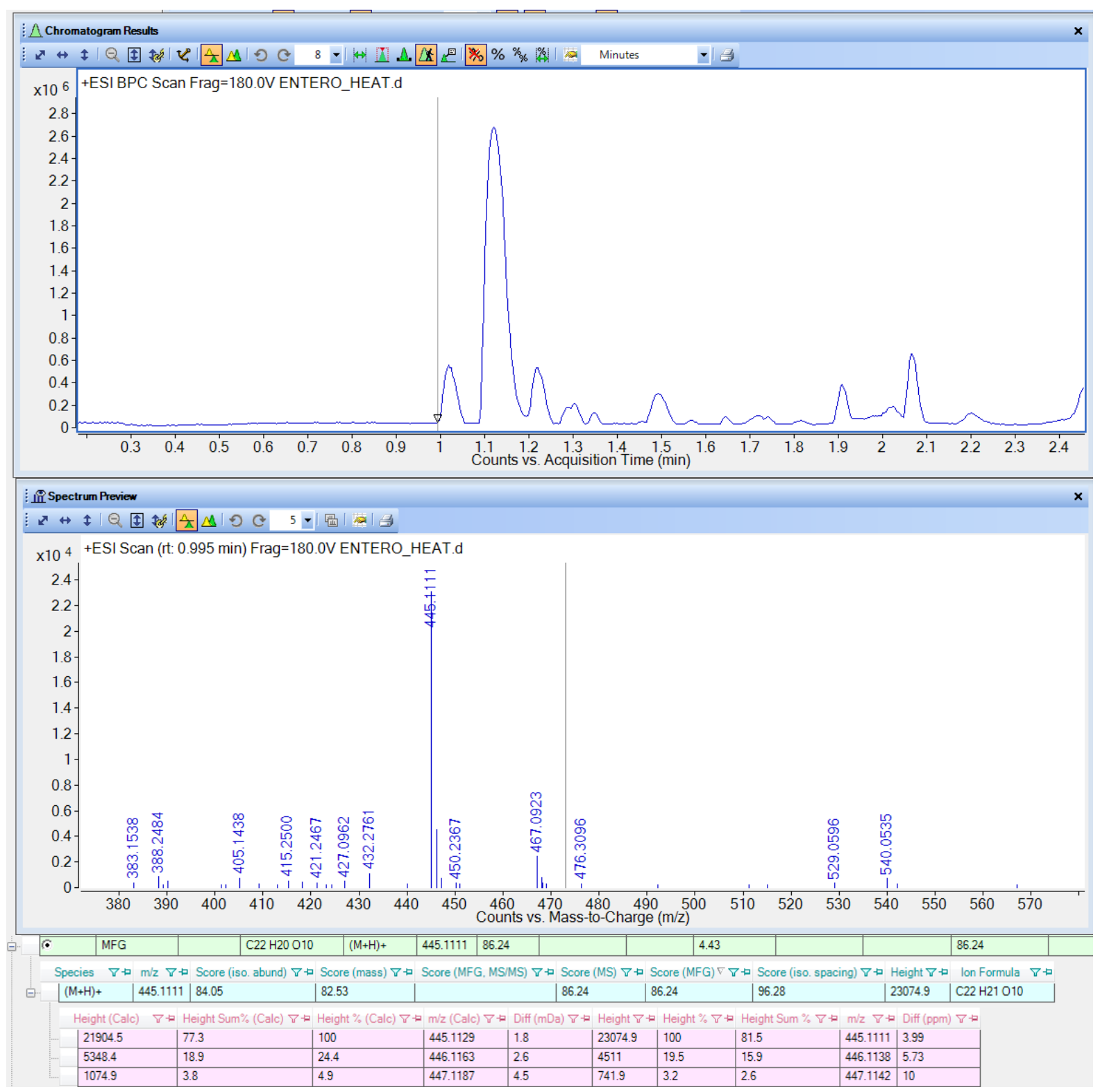

Figure S30. UPLC-QTOF spectrum and HRESIMS measurement for enterocin B (6). 


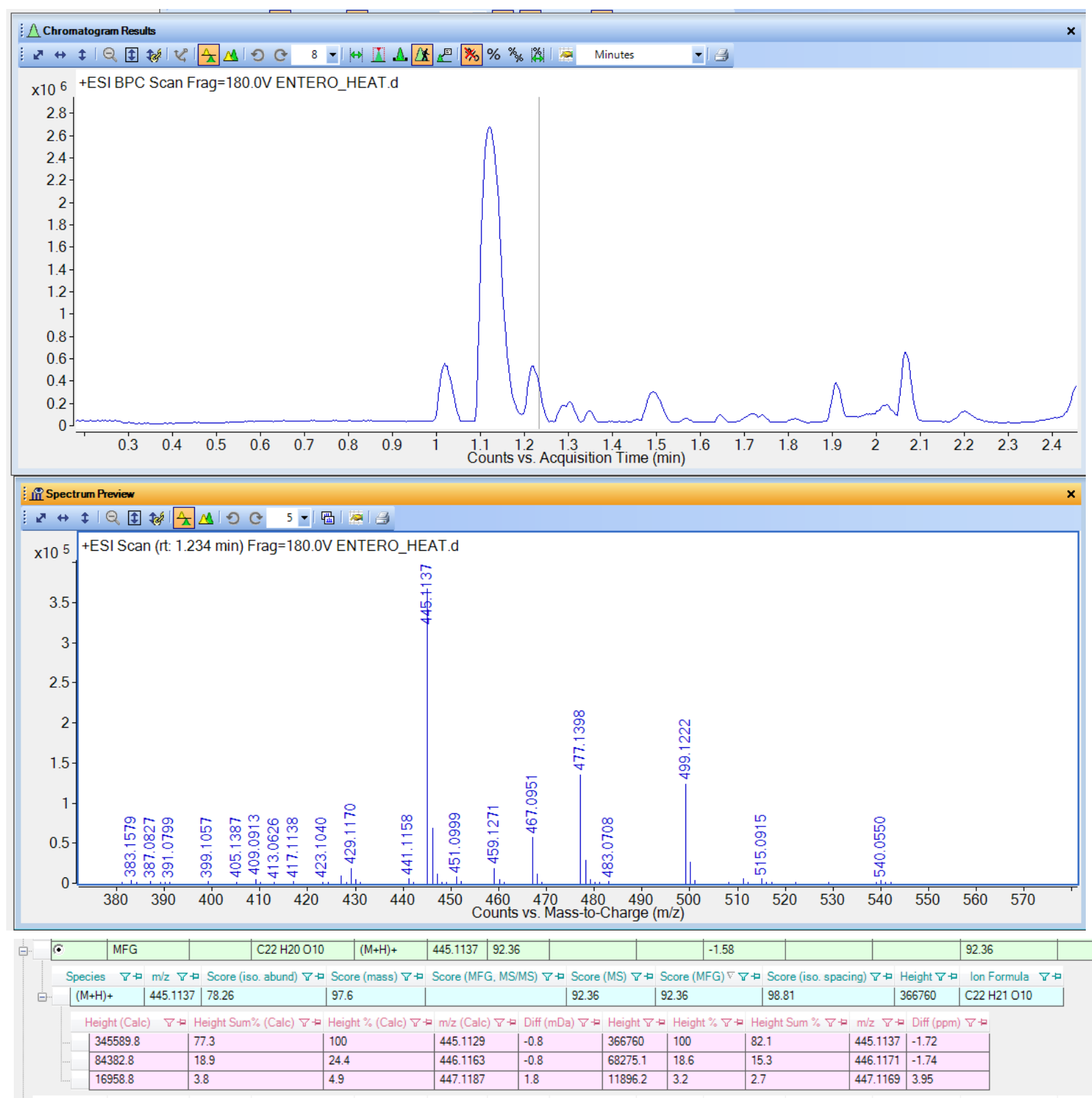

Figure S31. UPLC-QTOF spectrum and HRESIMS measurement for enterocin C (7). 


\section{Mass Spectrum Molecular Formula Report}

Analysis Info

Analysis Name

Method

D:IDatala.salimlenterocin D meoh.d

tune-med_AP.m
Acquisition Date $\quad 1 / 31 / 2020$ 10:52:34 AM

Operator

Instrument / Ser\# micrOTOF 213750.00

Comment

\begin{tabular}{|c|c|c|c|c|c|}
\hline \multicolumn{6}{|c|}{ Acquisition Parameter } \\
\hline Source Type & ESI & Ion Polarity & Positive & Set Nebulizer & $0.8 \mathrm{Bar}$ \\
\hline Focus & Not active & & & Set Dry Heater & $180^{\circ} \mathrm{C}$ \\
\hline Scan Begin & $100 \mathrm{~m} / \mathrm{z}$ & Set Capillary & $4500 \mathrm{~V}$ & Set Dry Gas & $5.0 \mathrm{l} / \mathrm{min}$ \\
\hline Scan End & $1000 \mathrm{~m} / \mathrm{z}$ & Set End Plate Offset & $-500 \mathrm{~V}$ & Set Divert Valve & Source \\
\hline
\end{tabular}

Generate Molecular Formula Parameter

Formula, min.

Formula, max.

Measured $\mathrm{m} / \mathrm{z}$

Check Val

Nirogen R

Filter H/C Ratio

Minimum

Electron Configuration

Minimum

Charge

Maximum

Estimate Carbon

Maximum
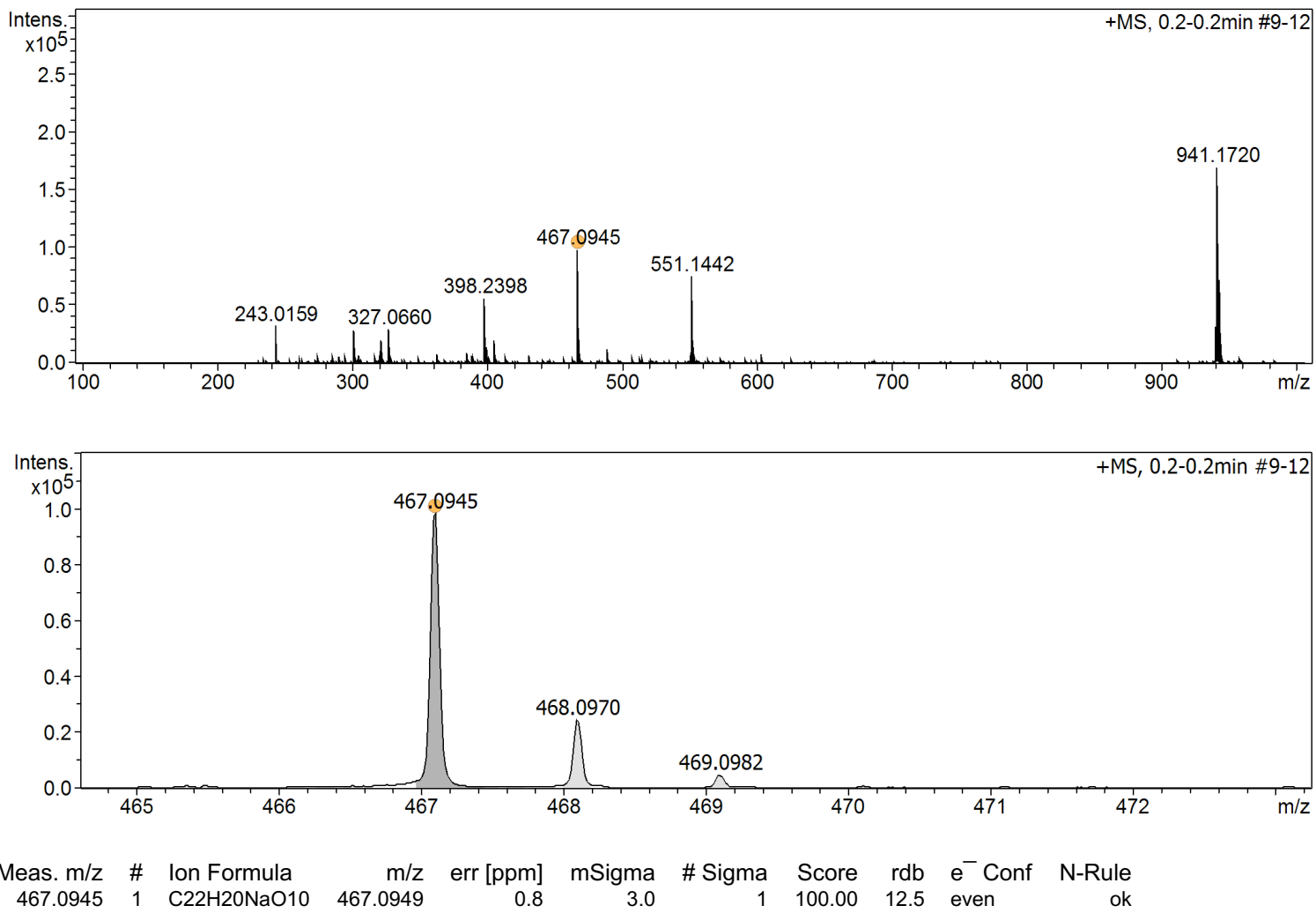

Figure S32. HRESIMS spectrum and measurement for enterocin D (8). 


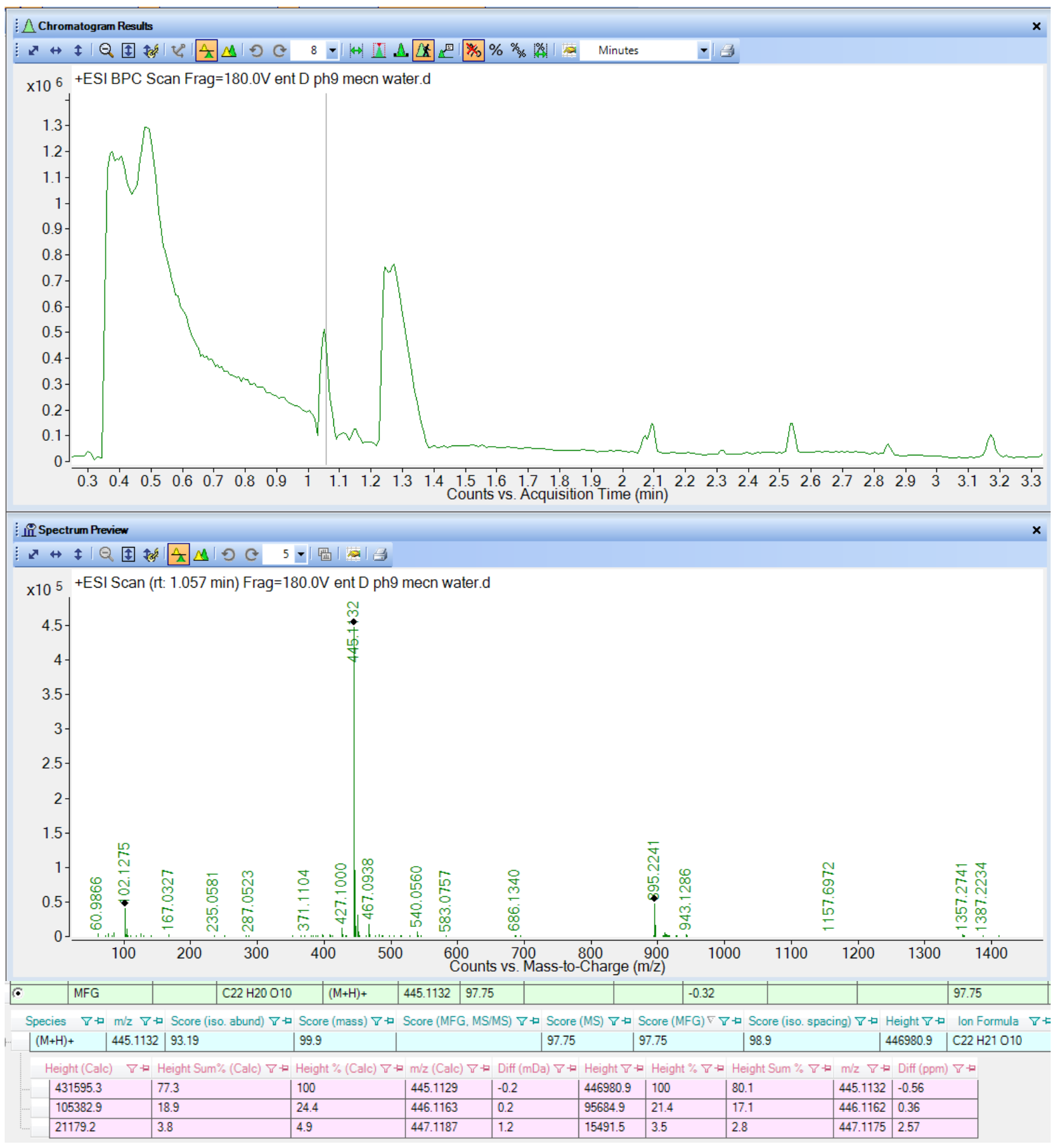

Figure S33. UPLC-QTOF spectrum and HRESIMS measurement for enterocin E (9). 


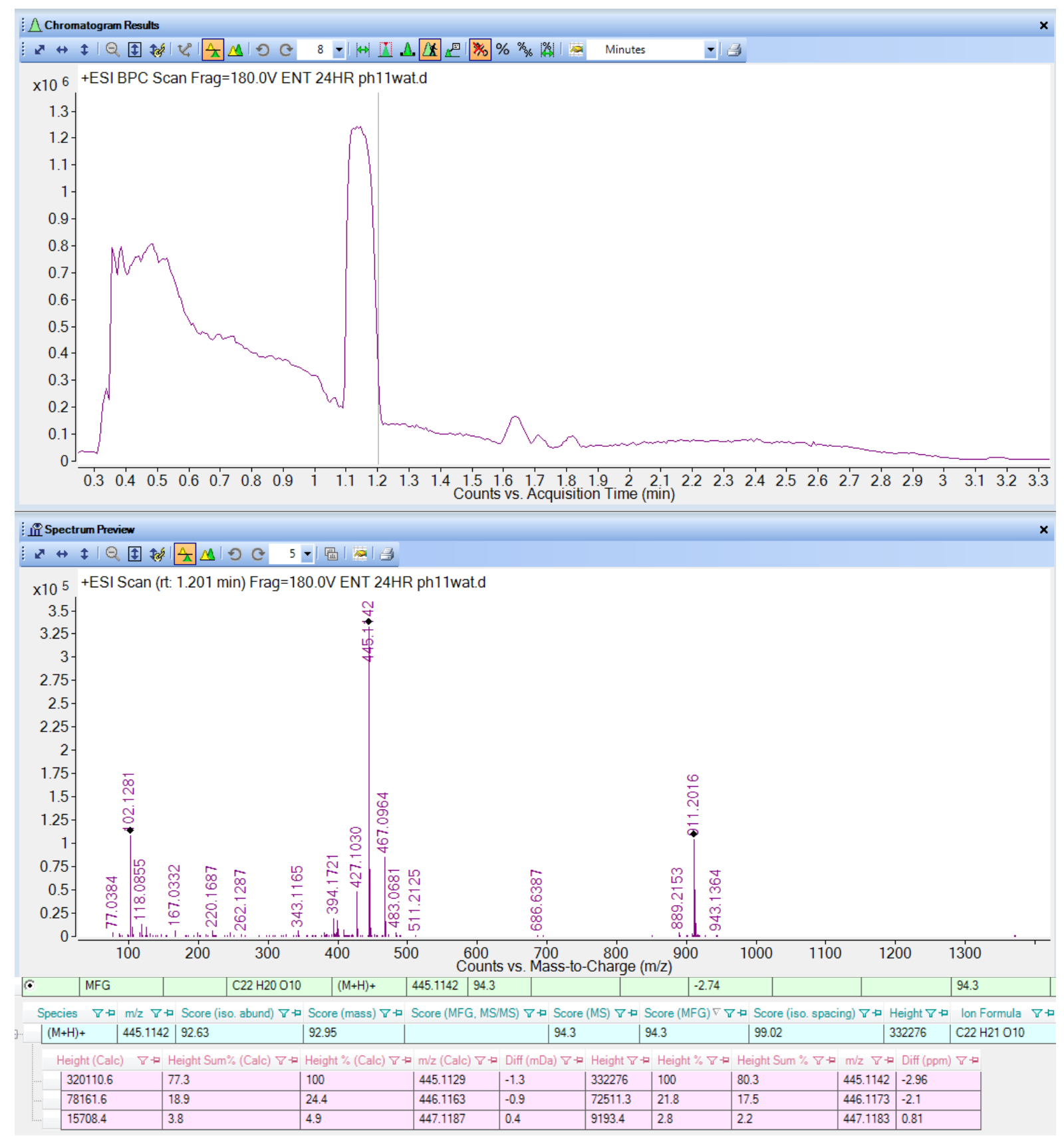

Figure S34. UPLC-QTOF spectrum and HRESIMS measurement for enterocin F (10). 